\title{
ANÁLISE DIALÉLICA ENVOLVENDO DEZ PARENTAIS SEMI-PRECOCES DE SOJA (GIyeine max (L.) MERRILL)
}

\author{
MILTON KRIEGER \\ Engentieiro Agrónomo
}

Orientador: Prof. Dr. NATAL ANTONIO VELLO

\begin{abstract}
Dissertação apresentada à Escola Superior de Agricultura "Luiz de Queiroz", da Universidade de São Paulo, para obtenção do título de Mestre em Agronomia, Area de concentração: Genética e Melhoramento de Plantas.
\end{abstract}

PIRACICABA

Estado de São Paulo - Brasil

Janeiro - 1992 
Ficha catalográfica preparada pela Seção de Livros da Divisão de Biblioteca e Documentação - PCLQ/USP.

\footnotetext{
Krieger, Milton

K92a Análise dialélica envolvendo dez parentais semiprecoces de soja (Glycine max (L.) Merrill). Piracicaba, 1992.

$65 p$.

Diss. (Mestre) - ESALQ

Bibliografia.

1. Genética quantitativa 2. Soja - Cruzamento dia Iélico 3. Soja - Melhoramento I. Escola Superior de Agricultura Luiz de Queiroz, Piracicaba.

$\operatorname{CDD} 633.34$
} 


\section{ANÁLISE DIALÉLICA ENVOLVENDO DEZ PARENTAIS SEMI-PRECOCES DE SOJA}

MILTON KRIEGER

Aprovada em: 05.03.92

Comissão Julgadora:

Prof. Dr. Natal Antonio Vello ESALQIUSP Prof. Dr. Roland Vencovsky ESALQIUSP Prof. Dr. Carlos Jorge Rossetto IAC/Campinas

$$
\begin{aligned}
& \qquad M-1<1.115 . \\
& \text { Prof. Dr. Natal Antonio Vello } \\
& \text { Orientador }
\end{aligned}
$$


Aos meus pais dedica, e a todos ofereco. 


\section{AGRADECIMENTOS}

Ao Prof. Dr. Natal Antonio Vello pela amizade, colaboração e valiosa orientação.

Ã Fundação de Amparo à Pesquisa do Estado de São Paulo (FAPESP) e ao Departamento de Genética da Escola Superior de Agricultura "Luiz de Queiroz" (ESALQ/USP), que tornaram possivel a realização desta pesquisa.

AO CNPq, EMBRAPA $P$ FAPESP pElo apoio financeiro concedido às pesquisas do Setor de Genética Aplicada às Espécies Autógamas.

Aos professores do Departamento de Genetica da ESALQ pelos ensinamentos, em particular aos professores Geraldo Antonio Tosel10, Gerhard Bandel e Jose Branco Miranda Filho que juntamente com o Prof. Natal A. Vel10, compuseram a banca do meu exame geral de qualificaçăo.

Aos colegas Carlos Eduardo Pires, Dario Hiromoto, Diego Soldini, Eduardo Brás Pacóva, Gilberto Keniti Yokomizo, José Baldin Pinheiro, Juan Carlos Montaño, Lé Zimback, pelo apoio $e$ colaboraçăo nos trabalhos experimentais.

Aos funcionários do Departamento de Genética, em especial aos Srs. Antonio Roberto Cogo, Claudinei Antonio Didone, José Roberto Alonso e Osmair Jose da Silva, 
pela dedicação na realização dos trabalhos de campo e laboratorio.

Ao Centro de Informática na Agricultura (CIAGRI) pelas instalaçBes cedidas e aos seus funcionários pelos trabalhos prestados, em especial a Lilian Cristina Anefalos pela valiosa colaboração nas análises estatisticas. Ao Setor de Cursos de Pós-Graduação da ESALG' USP pela atençăo e competencia dispensadas no atendimento durante o periodo do curso. 
SUMARIO

Página

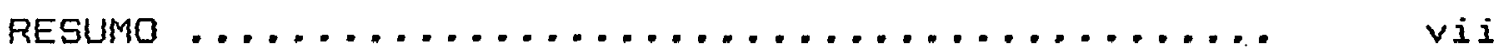

SUMMARY ...........................

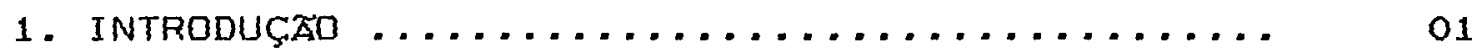

2. REVISAT DE LITERATURA ............... o.

2.1. Vulnerabilidade .................. 09

2.2. Análise dialélica ................. 11

3. Material e metodos ......................... 15

3.1. Caracteres avaliados ................ 17

3.2. Análise de variância ................. 18

3.3. Analise dialblica ................... 19

3.4. Heterose e heterobeltiose .............. 19

3.5. Herdabilidade .................... 20

4. Resultados e discussto ................... 21

4.1. Número de dias para o florescimento ...... 22

4.2. Altura da planta no florescimento ........ 23

4.3. Número de dias para maturação ........... 24

4.4. Altura da planta na maturação .......... 24

4.5. Acamamento e valor agronómico .......... 25

4.6. Produção de grãos por planta ........... 27

4.7. Análise de GRIFFING ............... 28

4.7.1. Capacidade geral de combinação .... 29

4.7.2. Capacidade especifica de combinação 29

4.7.3. Análise dialélica ............ 29

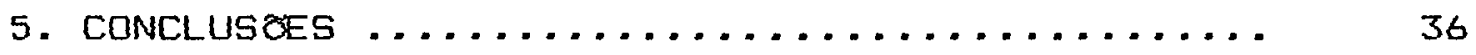

REFERENCIAS BIBLIOGRAFICAS ............... 38

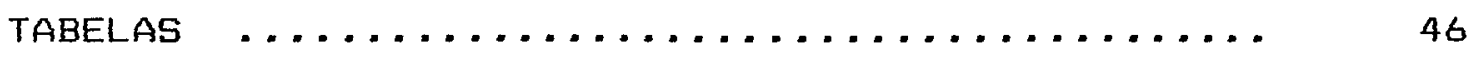


ANAL ISE DIALELICA ENUOLVENDO DEZ PARENTAIS SEMI-PRECOCES DE SOJA (GIycine max. (L.) Merri11)

Autor: Milton Krieger

Orientador: Prof.Dr. Natal Antonio Vello

\section{RESUMO}

Em 1983, teve infcio no Departamento de Genética ESALQ/USP, um programa que visa integrar a obtenção de populaçßes não tendo diferentes graus de base genética, com a prática de seleção recorrente a partir dos intercruzamentos de 40 parentais $(10$ precoces, 10 semi-precaces, 10 semitardios e 10 tardios), selecionados prinicipalmente para produtividade e diversidade genética.

Esta pesquisa teve por objetivo a avaliação de 45 cruzamentos dialelicos (geração $F_{2}$ ) entre os dez parentais de soja semi-precoces: Davis, Bossier, Vicoja, IAC-10, IAC-12, IAC-1, BR-1-FosCa, GO 81-11646, SOC 81-228 e FT $81-2706$.

Foram avaliados os seguintes caracteres: tempo para o florescimento, altura da planta no florescimento, tempo para a maturidade, altura da planta na maturidade, produção de grãos por planta, valor agronômico e acamamento. 
A análise de Griffing revelou maior importância da capacidade geral de combinação (CGC) em relação à capacidade especl fica de combinação (CEC), sendo a razăo CGC $/$ (CGC + CEC) superior a 0.9 em todos os caracteres. As estimativas do efeito geral da capacidade de combinaçăo (gi), do efeito da capacidade especifica de um parental com ele mesmo (Sii) e do efeito da capacidade especifica de combinaça para o cruzamento entre dois parentais (Sij para $i \neq j$ ), apresentaram variaçăo em todos os caracteres. No carater produtividade (PPI), os parentais GO 81-11646, IAC-12 e IAC-1 obtiveram as melhores estimativas para capacidade geral de combinação gi; alem disso, participaram dos cruzamentos mais expressivos para esse caráter. As estimativas dos parámetros geneticos serão empregadas para orientação da sintese das populaçßes. 


\section{DIALLEL ANALYSIS OF TEN SEMI-EARLY SOYBEAN \\ (GIycine max (L.) MERRILL) PARENTS}

Author: Milton Krieger

Adviser: Prof. Dr. Natal Antonio Vello

\section{SUMMARY}

In 1983, it was initiated in the Genetics Department of ESALQ/USP a program aiming to integrate the synthesis of populations having different degrees of genetic base, with the practice of recurrent selection from the intercrosses of 40 parents (10 early, 10 semi-early, 10 semi-late and 10 late genotypes) selected for seed yield and genetic diversity.

This research had the objective of evaluating 45 diallel crosses (F2 generation) among the 10 semi-early soybean parents: Davies, Bossier, Viçoja, IAC-10, IAC-12, IAC-1, BR-1-Fosca, GO 81-11646, SOC 81-228 and FT 81-2706. They were evaluated the following traits: time to flowering, plant height at flowering, time to maturity, plant height at maturity, seed yield per plant, agronomic value and lodging. 


Griffing's analysis revealed that general
combining ability (gca) was much more important than
specific combining ability ( sca ); the relation
gca/ (gca + sca) was superior to 0.9 for all characters.
The parents $6081-11646$, IAC-12 and IAC-1 presented the
largest values of general combining effect and participated
in crosses with superior seed yield. The genetic parameters
will be applied to manage the synthesis of populations.




\section{INTRODUÇÃO}

A soja vem se tornando a principal oleaginosa em produção sob cultivo intenso, mesmo se considerando sua introdução relativamente recente na cultura ocidental. $\mathrm{Na}$ epoca colonial, apenas a China exportava quantidades notaveis de soja que, naquela ocasião, era pouco contrecida nos Estados Unidos, hoje primeiro produtor mundial.

a cultivo da soja se desenvolveu no Novo Mundo na decada de 30. Em 1949, quando a revolução chinesa suspendeu subitamente as exportaçóes de soja da Manchúria, os Estados Unidos assumiram as exportaçóes chinesas e se tornaram desde então os maiores exportadores de soja.

Tanto os Estados Unidos como a Europa adotaram um modelo de modernização da agricultura, em que a soja é um dos pilares de sustentação. Inúmeros paises do Terceiro Mundo e do leste europeu seguiram, em graus diversos, esse madelo no correr dos últimos anos. A soja torna-se então uma das principais culturas (BERTRAND et alii, 1987).

A modernização da pecuária européia torna-se totalmente dependente da soja, colocando a Europa no pri- 
meiro posto entre os importadores de soja americana. Com o passar dos anos, a Europa bem como o japão e os passes do leste europeu aumentaram rapidamente suas importaçôs.

Em 1973, o Brasil, que ja produzia mais de quatro milhós de toneladas de grão de soja por ano, apresenta-se como parceiro aos passes importadores. Apesar de desconhecida da maioria dos brasileiros a soja se impöe e a partir da década de 80, ela ocupa $16 \%$ das terras agriculturáveis do pais. Em 1985, sua cultura estendia-se por mais de 10 milhoses de hectares e a produção beirava os 18 milhões de toneladas; mais de um em cada cinco hectares cultivados estava plantado com soja. Bastaram 15 anos, de 1965 a 1980 para passar de $1,4 \%$ a $16 \%$ da produção mundial, sendo que em 1985 a porcentagem era de $19 \%$. O bleo de soja teve seu consumo per capita aumentado de 1,2 kg por ano em 1964-65, para mais de $13 \mathrm{~kg}$, em 1980 (BERTRAND et alii, 1987).

Segundo a FAO (1991), a produção mundial de soja é de 108,150 milhzes de toneladas, cabendo aó Brasil a produçăo de 19,8 milhøes de toneladas. Entretanto, segundo dados do IBGE (LAZZARINI \& DITT, 1991a,b), a produção brasileira na última safra foi de 14,4 milhoes de toneladas, e a nossa safra $91 / 92$ não deve superar a úlima, pois houve diminuição na área plantada de $50 j a$.

A análise de dados sobre produção, geralmente feito em milhōes de toneladas, não dăo ao leitor comum uma ideia do volume de soja produzido no Brasil. Com base em 
dados do Ministério da Saúde, de que a necessidade de protesna ede $15 \mathrm{~kg}$ de proteina por ano por habitante, mais o resultado do censo e dados oficiais sobre o desempentio da lavoura, TENDRIH (1987) demonstrou que desde 1980 , nosso pais exporta a cada ano uma quantidade de soja que corresponde a quase o dobro das necessidades proteicas de toda sua popul ação.

Entre os métodos classicos de melhoramento, o da introdução foi o mais importante na difusão da soja para - ocidente. A introdução de variedades e linhagens oriundas da China, Manchúria, Japão e outros países orientais, constitui-se na base inicial para o desenvolvimento da soja nos paises produtores do ocidente. Posteriormente, outros métodos aplicados as especies autógamas foram usados na soja. Entretanto, a estreita base genética da soja, aliada aos metodos convencianais de melhoramento, torna a cada dia, mais dificil de se suplantar patamares de produtividade, além dos riscos da vulnerabilidade genetica.

Para solucionar este problema, iniciou-se em 1983 no Departamento de Genética da ESALQ/USP, um programa que tem por objetivo integrar a síntese de populaçós de soja com base genética ampla com a pratica de seleção recorrente (VELLO, 1992a).

Foram selecionados 40 parentais, sendo dez para cada grupo de maturidade: precoce, semi-precoce, semitardio e tardio. Estes parentais foram escolnidos com base 
na produtividade e divergencia genética, a partir dos resultados obtidos em experimentos conduzidos em tres locais (Anhembi, Piracicaba e Sertãozinho) durante os anos de $1983 /$ 84 e $1984 / 85$.

0 esquema de recombinação (Apêndice 1) envolve quatro dialelos 10x10, com 45 cruzamentos biparentes para cada grupo de maturidade, somando 180 cruzamentos no total. A segunda recombinação compreende 45 cruzamentos quádruplos entre os hibridos $F_{1}$ precoces e semi-precoces e 45 cruzamentos quadruplos entre os hibridos $F_{1}$ tardios $e$ semitardios. A terceira recombinação produzirá 45 cruzamentos octuplos dos Fi's (precoce $x$ semi-precoce) com os Fi's (semi-tardio $\times$ tardiol.

Esta pesquisa tem por objetivo a avaliação dos 45 cruzamentos dialelicos (geração $F z$ ) entre dez parentais de soja semi-precoces.

Foram avaliados os sequintes caracteres: tempo para o florescimento, altura da planta no florescimento, tempo para a maturidade, altura da planta na maturidade, produção de grãos de plantas individuais, acamamento e valor agronómico.

As estimativas de parâmetros genéticos (heterose, herdabilidade, capacidade geral e especifica de combinaçã serão empregados para orientação da síntese de população com base genética ampla e alta produtividade de ตัธัธธ. 


\section{REVISÃo DE LITERATURA}

o melhoramento genetico de qualquer especie de planta pode ser dirigido essencialmente visando duas alternativas: (a) obtenção de uma população melhorada, ou (b) exploração de heterose, ou seja, obtençăo de Fi's com vigor hibrido (PATERNIANI \& MIRANDA FILHO, 1985), sendo que o esquema geral de um programa de melhoramento apropriado a uma espécie é determinado, em grande parte, pelo sistema reprodutivo da especie (ALLARD, 1960 ).

o melhoramento de autógamas, basicamente consiste na hibridaçăo de um número pequeno de genótipos, seguidos de um dos processos de avanço de geraçôes segregantes durante várias geraçơs, até a obtenção de genótipos homozigóticos. No entanto, para caracteres cujo controle 6 efetuado por inúmeros genes, como produção de grãos, altura da planta, etc., o progresso obtido pelo emprego dos métodos tradicionais de melhoramento năo são acentuados. Tal ocorre na soja, onde geralmente são observados pequenos progressos por seleção (BRIM, 1973). 
FEHR (1978) analisou um suposto incremento de $100 \mathrm{~kg} / \mathrm{ha}$ por ciclo de seleção, na produção de um cultivar de soja, utilizando-se os métodos tradicionais, e com uma geração por ano. O autor conclui que seriam necessários 19 anos de trabalho para obtença de $300 \mathrm{~kg} / \mathrm{ha}$ a mais, em um cultivar. Bs progressos lentos obtidos são, em parte, devido à pequena variabilidade existente nos cruzamentos realizados de forma tradicional. JENSEN (1970), observa que - emprego de um reduzido número de genotipos usados na formação do lote inicial de eruzamentos mais as limitaçठ̄es dos processos de seleçăo, săo as causas possiveis dos baixos incrementos nas produços da cultura.

As teorias de seleção empregadas nas métodas tradicionais visam identificar genotipos superiores. Entretanto, nestes processos, aspectos como a estrutura genetica da população, as ações genicas envolvidas no caráter e a magnitude da variabilidade presente, normalmente não são considerados. Com o advento das teorias e métodos de genética quantitativa foram proporcionadas melhores condiçöes de ganto genético nas espécies agricolas. Isto se deu pela utilização adequada de processos seletivos. Gutra vantagem do emprego da genética quantitativa como instrumento auxiliar na escolha do método de melhoramento a ser utilizado, deve-se ao fato do conhecimento das ações gênicas envolvidas e da estrutura genetica per se dos genotipos parentais dos cruzamentos. A produção de grãos em soja é uma carac- 
teristica essencialmente quantitativa. JOHNSON \& BARNARD (1963) conclufram que variancia genetica aditiva parece ser a principal componente para produção de grãos.

$$
\text { Foi Fisher (1918), citado por ALLARD (1963), }
$$

quem primeiro procurou fazer uma partição da variância genotípica em suas partes componentes. Este reconheceu três componentes da variancia genética: 1) uma parte aditiva devido a diferença entre os homozigotos de cada loco; 2) uma componente dominante originada da interaçăo entre alelos (interação alelica); 3) uma parte epistatica associada à interação entre não alelos (interação não alelica).

Os relatos de JOHNSON \& BERNARD (1963), evidenciaram a importáncia do adequado aproveitamento da variancia genética aditiva, embora BRIM (1973), chame a atenção de que as açชes genicas do tipo aditivo $x$ aditivo não devem ser desprezadas, ou mesmo as responsáveis por combinações hetezigóticas favoráveis.

Com o sentido do aproveitamento da ação gênica aditiva, que autores como HANSON et alii (1967) e COMPTON (1968), recomendam o emprego de esquemas de seleção recorrente em soja, haja visto resultados promissores em plantas alogamas (SPRAgUE, 1967). Do ponto de vista genetico, KHADR \& FREY (1965), argumentam que nã existe impedimento para utilização de seleção recorrente em espécies autógamas. No entanto, a utilizacão plena de esquemas de seleção recorrente é limitada na soja (BRIM, 1973); essas 
limitaçชes să causadas pelas dificuldades naturais existentes na obtenção de niveis adequados de recombinantes desejados causados pela dificuldade para realização de um número suficiente de cruzamentos, pequeno número de sementes por cruzamento, tempo necéssario para avaliação das progênies e limitaçós nas metodologias empregadas para avaliação de progênies. Estas mesmas limitações podem ser feitas para a exploração da heterose.

BRIM \& YOUNG (1971) identificaram um par de genes recessivos (msimsi) responsável pelo caráter macho-esteril. Segundo os autores, $99 \%$ ou mais das sementes obtidas de plantas macho-estereis, eram devidas à cruzamentos naturais. Entretanto, apesar da porceritagem de cruzamentos naturais ser elevada, a número de sementes obtidas era reduzido por planta, sendo em média de 40 sementes (BURTON \& BRIM, 1981). No entanto, devido a algumas limitaçB̃es citadas anteriormente, esta media b superior às possiveis de serem obtidas por ciruzamentos artificiais. Segundo FEHR \& ORTIZ (1975), O emprego do carater macho-esteril em cruzamentos, permite a eliminação das polinizaçóses artificiais e reduz o tempo necessário para completar o ciclo de seleção.

Qutros trabalhos envalvendo o uso de seleção recorrente com macho-esterilidade em soja foram feitos por KENWORTHY \& BRIM (1979) E BRIM \& BURTON (1979).

SEDIYAMA et alii (1981), argumentam que a 
produção total de grãos depende do conjunto de vários fatores. Todavia, entre os fatores geneticas destacam-se o tamantio e o peso da semente, o número de sementes por planta, os quais, dependem do maior vigor da planta e de um perfodo de frutificação mais longo.

Quanto ao tempo para maturidade e florescimento, esses caracteres parecem ser influenciados por poucos genes maiores e alguns genes menores. Vários autores estudaram esses caracteres, dentre esses se destacam SINGH \& ANDERSON (1949), BERNARD (1971), BUZZEL (1971); KHIIL (1976), BUZZEL \& VOLDENG (1980), TOLEDO \& KHIIL (1982a,b); McBLAIN \& BERNARD (1987) e mais recentemente por BONATO (1989).

\subsection{Vulnerabilidade}

As principais culturas são muitas vezes bastante uniformes geneticamente e muito vulneráveis, sendo que - fornecimento de alimentos para o mundo, depende da conservação e melhor utilização dos recursos genéticos. Além do risco de epidemias, a falta de diversidade causa a formaçăo de patamares de produtividade, sendo estes os principais efeitos da base genética estreita.

A seleção efetiva é dependente da variabilidade genética. Entretanto, esses ganhos são acompanhados de 
um aparente risco de vulnerabilidade genetica devido ao estreitamento da base genetica. O problema surge também devido à concentração de cultivares "lideres"; nos Estados Unidos, seis dos mais "populares" cultivares de soja americanos representam $42 \%$ do total plantado (DUVICK, 1984). DELANNAY et alii (1983) examinaram as genealogias de 158 cultivares de soja dos Estados Unidos e Canadá, indicando que o "pool" gênico poderia ser traçado para 50 introduçธ̋es. Os autores avaliaram a contribuição genetica relativa desses introduçôses nos "pools" gênicos do norte e do sul dos Estados Unidos para quatro periodos; antes de 1951, 1951-1960, 1961-1970 e de 1971-1981. Embora mais introduçōes tenham sido usadas em tempos recentes, poucas constituem grande parte da base genetica dos cultivares modernos, sendo que dez introduç̧es contribur ram, com mais de $80 \%$ do "pool" génico do norte, enquanto que so sete contribufram para a mesma quantidade do"pool" gênico do 5ul. E mais, muitas introduções predominantes, originaram-se na mesma região geografica. HIRoMoto \& VELLO (1986) estudaram a situação da base genética no Brasil. Os resultados dessa pesquisa foram de certa forma semelhantes ans encontrados por DELANNAY et alii (1983) nos Estados Unidos. Segundo a estudo de HIROMOTO \& VELLO (1986) as cultivares brasileiros poderiam ser traçados em relação a 26 ancestrais, sendo que 11 representam coletivamente $89 \%$ do "pool" genico brasileiro. 
A media geral do coeficiente de parentesco de 69 Variedades brasileiras de soja foi calculado por VELLO et alii (1988) dando um valor de 0,16 . Os autores compararam também este coeficiente médio com os estimados nos Estados Unidos e Argentina, que são respectivamente 0,23 e 0,16 , sendo que o programa de melhoramento no Brasil e Argentina são mais recentes que o dos Estados Unidos. Os autores informam ainda que o germoplasma de soja dos Estados Unidos contribuiu significativamente ao germoplasma brasileiro, e que ambos contribuiram ao estabelecimento do programa de soja argentino.

VELLO (1985) relata que o material cultivado na região sul dos Estados Unidos (grupos $V$ a $x$ ) 'é o que apresenta maiores chances de adaptação em condiçßes semitropicais e tropicais. E interessante notar que a base genetica do germoplasma cultivado no 541 dos Estados Unidos é a mais estreita, de acordo de DELANNAY et alii (1983).

\title{
2. 2. Análise dialélica
}

\begin{abstract}
A análise dialélica envolve os cruzamentos possiveis de serem realizados, entre um grupo de $\mathbf{n}$ linhagens, variedades ou populações. Podem incluir, ou não, os tipos parentais, bem como os reciprocos.
\end{abstract}

Basicamente, existem trés metodologias para 
análise dialelica; GARDNER \& EBERHART (1966), HAYMAN $(1954 a, b)$ e GRIFFING $(1956 a, b)$.

SEgundo VENCOVSKY (1971) o metodo de GARDNER \& EBERHART (1966) é especifico para cruzamentos entre variedades em equilibrio de Hardy-Weinberg. Esse mesmo autor rejata que o processo de análise proposto por GARDNER \& EBERHART (1966) foi desenvolvido devido ao crescente interesse em torno de cruzamentos intervarietais em milho (VENCOVSKY, 1969). Entretanto, PALUDSYZYSYN (1982) utilizou esta metodologia para avaliar um dialelo $8 \times 8$ em soja com bons resultados.

A metodologia de $\operatorname{HAYMAN}(1954 a, b)$ se baseia nas seguintes suposiçōes: a) segregaça do diploide; b) ausencia de efeitos reciprocos entre cruzamentos; c) aça independente de genes não alelicos, ou seja, ausencia de epistasia; d) ausencia de alelos múltiplos; e) linhagens parentais homazigóticas; f) genes independentemente distribuidos nos parentais. A segregação diplóide e uma caracterfstica normal da especie, os demais requisitos também devem 'ser razoavelmente atingidos. Contudo, no que se refere à ausencia de alelos múltiplos e particularmente à ausencia de epistasia é provável que haja desvios. Entretanto, o próprio modelo testa esses desvios, e so devem ser aplicado quando os mesmos não forem significativos. A metodologia de HAYMAN (1954a,b), é um poderoso meio de elucidar sistemas poligênicos. A sua utilização e indicada para 
linhagens puras, sendo, por isto, utilizadas em plantas de auto-fertilização.

A análise de GRIFFING $(1956 a, b)$ é fundamentada num modelo estatistico, sendo amplamente utilizada em especies alogamas e autógamas. A metodologia é aplicável para quatro tipos de tabelas dialélicas, com cálculos de análise da variância e estimação de efeitos de capacidade geral e especifica de combinaçăo, segundo dois modelos: fixo e aleatorio.

CRUZ \& VENCOUSKY (1989) estudaram as interrelaçós existentes entre os efeitas descritos na metodologia proposta por GRIFFING (1956), modelos 2 e 4 e os efeitos descritos na metodologia proposta por GARDNER \& EBERHART (1966). Os autores também discutem a importância e significado genetico do parámetro sii referente à capacidade especifica de uma variedade com ela mesma. Para esses autores, de um modo geral, gi continua sendo o melhor criterio para escoliha de parentais. A decomposição deste parâmetro em $V_{i} e$ hi (GARDNER \& EBERHART, 1966) não trouxe grande contribuiçăo adicional.

Em soja a metodologia mais usada de Griffing, mais precisamente o método 2 . No método 2 são usados os parentais e o conjunto de Fi's sem as reciprocas. Esse modelo pode também ser usado com fa's (SRIVASTaVa, 1978; NASS, 1988; FREIRE FILHO, 1988). Também se usou F's em trigO (TALUKDAR \& BAING, 1989). 
BAKER (1978) estudou a importancia da capacidade geral e especifica de combinação e fez um paralelo entre os métodos de análise dialelica e suas aplicaçôs.

A capacidade geral de combinação decorre principalmente da variância genetica aditiva e da variância epistática aditiva $x$ aditiva, e a capacidade especifica resulta da variância genética dominante e vários tipos de componentes de variancia epistática (GRIFFING, $1956 a$ e KEMPTHORNE \& CURNOW, 1961).

LEFFEL \& WEISS (1958), encontraram alta capacidade especifica para algumas linhagens (menos produtivas) e alta capacidade geral de combinação para outras las mais produtivas). WEBER et alii (1970) mediram a heterose num grande número de cruzamerntos durante quatro anos. Mais de 75\% dos híbridos apresentaram heterose para produção, a que os levou a concluir que a açăo gênica não aditiva estava envolvida na expressão desse carater. A conclusão foi reforcada pelo efeito significativo devido à capacidade especifica de combinação. 


\section{MATERIAL E MÉTODO}

Foram realizados aproximadamente 1000 hibridaçōes manuais para abtenção dos 45 cruzamentos dialélicos entre os dez parentais: Davis, Bossier, Viçoja, IAC-10, IAC-12, IAC-1, BR-1-Fosca, GO 81-11.646, SOC 81-228 e FT 81-2706. As genealogias dos parentais se encontram no Apêndice 2 .

0 avanço da geraça de Fi para Fz, foi feito atraves de autofecundaçós naturais no campo. As sementes Fi foram semeadas em covas espaçadas em un metro uma da outra, usou-se quatro sementes por cova sem desbaste. As plantas $F_{1}$ foram estaqueadas.

0 experimento em látice $8 \times 8$ com seis repetif̧os das 45 progenies Fz's, dez parentais e mais nove tratamentos adicionais para completar o látice, foi ao campo em 21 de novembro de 1989.

As sementes foram plantadas em covas com tres a seis sementes por cova, dependendo da disponibilidade de sementes. O desbaste foi feito duas semanas após a emergência, deixando-se apenas uma planta por cova. 
As parcelas foram constituidas de 12 covas, espaçadas $0,6 m$ uma da outra, formando uma parcela de $8,40 m^{2}$. Como bordadura experimental foi usado o cultivar Stwart, que tem plantas altas de ciclo intermediário. As parcelas foram divididas em duas subparcelas de seis plantas cada, onde em cada subparcela havia sementes provenientes de fi's distintos; esse procedimento diminui pela metade as chances de se ter problemas com parcelas perdidas devido à autofecundação acidental durante a hibridação.

Foi efetuada uma pulverização contra parcevejos e uma aplicaçăo de "isca formicida" para o controle de saúvas. Não foi feita inoculação.

Os dados de florescimento foram tomados na abertura da primeira flor (Ri na escala de FEHR \& CAVINESS, 1977), enquanto que os dados da maturidade foram tomados quando pelo menos $95 \%$ das vagens estavam maduras, no estádio Ra da escala de FEHR \& CAVINESS (1977). Após a tomada dos dados de maturidade, cada planta recebeu uma etiqueta e foi coltida e trilhada individualmente.

\subsection{Caracteres avaliados}

As observações foram realizadas em plantas individuais; os dados coletados foram os seguintes: 
NDF: número de dias para o inicio do florescimento. Corresponde ao periodo entre a data de semeadura e a data da ántese da primeira flor.

APF : altura da planta no flarescimento. Compreende a distância entre o colo e a inserçă da inflarescencia mais distal da haste principal.

NDM: número de dias para maturidade. Correspondente ao periodo entre a data de semeadura ate aproximadamente $95 \%$ das vagens apresentarem-se maduras.

APM: altura da planta na maturidade. Compreendeu a distância entre o colo e a inserçăo da vagem mais distal da haste principal.

AC: acamamento. Avaliado na maturidade através de uma escala de notas visuais variando de 1 a 5 , onde a nota 1 correspondeu a uma planta ereta e a nota 5 a uma planta completamente acamada.

VA: valor agronómico. Avaliado na maturidade através de uma escala de notas visuais variando de 0 a 5, onde a nota zero correspondeu a uma planta sem nentum valor agronómico e a nota 5 a uma planta com excelentes características agronómicas.

PPI: produção de planta individual. Avaliada no laboratorio, onde cada planta foi pesada individualmente. A unidade utilizada foi gramas por planta. 


\title{
3.2. Análise de variância
}

\begin{abstract}
Foram realizadas duas análises de variância, sendo uma em látice e outra em blocos casualizados. A análise en latice foi feita de acordo com GOMES \& GARCIA $(1991)$

o modelo linear utilizado para análise em blocos casualizados baseou-se (FREIRE FILHO (1988); TOLEDO \& KIIHL (1982) E NASS (1989).
\end{abstract}

\section{3. Análise diaĺlica}

Utilizau-se a método 2 , modelo misto $B$, definido por GRIFFING $(1956 a, b)$. 0 método 2 compreende os parentais e o conjunto dos $n(n-1) / 2$ hibridos (progénies $F 2$ ), sem incluir as reciprocos. Nesse madelo, os efeitos de tratamentos são fixos e os de blocos e erro experimental são aleatorios. 0 uso do modelo misto $B$ decorre da escolha deliberada dos parentais. Isto implica em que as possiveis inferencias e conclusơes limitam-se ao material experimental utilizado no presente estudo.

Sendo os efeitos de tratamentos fixos; os objetivos básicos do estudo foram a comparação das capacidades de combinação dos parentais quando estes são usados como testadores. O esquema de análise de Griffing se en- 
contra na Tabela 8. A importância da capacidade geral de combinaçăo foi estimada pela relaçăo (BAKER, 1978):

$\frac{Q M_{C G C}}{Q M_{C G C}+Q M_{C E C}}$

3.4. Heterose e heterobeltiose

Sendo progênies F's, os resultados foram multiplicados por dois para que os mesmos fossem expressos ao nivel de $F_{1}$. As estimativas foram obtidas de acordo com FREIRE FILHO, 1988 E NASS, 1989 :

$$
\begin{aligned}
& \text { Heterose: } \frac{2\left(\bar{F}_{2}-\overline{M P}\right)}{\overline{M P}} \cdot 100 \\
& \text { Heterobeltiose: } \frac{2\left(\bar{F}_{2}-\overline{P S}\right)}{\bar{P} S} \cdot 100
\end{aligned}
$$

sendo:

$$
\begin{aligned}
& \bar{F}_{2}=\text { media da progénie } F_{2} \\
& \bar{M} P=\frac{P i+P j}{2}, \text { média dos parentais da progênie } F_{2}(i j) \\
& \overline{P S}=\text { media do parental superior. }
\end{aligned}
$$




\subsection{Herdabilidade}

A herdabilidade foi estimado no sentido
amplo, de acordo com FEHR (1987), sendo:
$h^{2}=\frac{5^{2} G}{S^{2} F}$

onde:

$$
\begin{aligned}
& S^{2} G=S^{2} F-S^{2} E \\
& S^{2} E=\sqrt{S^{2} P_{1} \times S^{2} P^{2}} .
\end{aligned}
$$

sendo:

$$
\begin{aligned}
& S^{2} G: \text { variancia genetica obtida dos componentes de } \\
& \text { variancia da tabela } 5 \text {; } \\
& S^{2} F \text { : variância fenotipica; } \\
& S^{2} \text { : variância ambiental; } \\
& S^{2} p 1 \text { e } S^{2} p 2: \text { variancia fenotipica dos parentais. }
\end{aligned}
$$




\section{RESULTADOS E DISCUSSÃO}

As plantas apresentaram excelente desenvolvimento vegetativo e reprodutivo. Devido à competiçăo minimizada do plantio em covas de plantas individuais, o vigor do crescimento vegetativo deveu-se principalmente à ramificação intensa, apesar da altura das plantas (media de $52 \mathrm{~cm}$ ) não ser elevada. Foi encontrada alta frequencia de plantas com ideotipo de cálice, caracteristica própria de plantas com ala produtividade e performance agronomica. Em média, as plantas produziram 74 gramas por planta (gpp), o que equivale a cerca de 500 sementes por planta. A performance agronómica altamente favorável, é explicada principalmente pela constituição genetica dos parentais. De fato, os genótipos do ciclo semi-precoce adaptam-se muito bem às condiçós ambientais encontradas no Estado de são Paulo. Alem disso, a performance agronómica tambem foi favorecida pelo cultivo em covas de plantas individuais espaçadas de $0.6 \mathrm{~m}$; estas condiçôs minimizam a competiçăo entre plantas e facilitam a observação e a avaliação das plantas. Năo houve eficiência do látice sobre blocos casualizados, ou seja, não houve efeito de retículos dentro 
das repetiçס̈es; o mesmo ocorreu com FREIRE FILHO (1988) e NASS (1989). Foi feito então a análise de variância para blocos casualizados, onde se constataram diferenças significativas para grupos de genótipos.

Os caracteres foram analisados a partir da media das observaçöes de plantas individuais. Os valores de AC E VA foram transformados para $\sqrt{x+1}$. Alquns parentais apresentaram variancias relativamente grandes, principalmente para NDF e NDM; isso leva à suposição de que esses parentais podem não estar totalmente homozigotos para esses caracteres. FREIRE FILHO (1988) e NASS (1989) também observaram isto nos parentais utilizados em seus estudos.

A precisão das análises foi avaliada através do coeficiente de variação, que apresentou niveis satisfatórios, sendo de certo modo, semelhantes nos coeficientes de variaçăo encontrados por FREIRE FILHO (1988), NASS (1989) e HIROMOTO (1990). Os coeficientes de variação (\%) foram: 6,6 (NDF), 12,8 (APF), 5,7 (NDM), 13,6 (APM), 16,2 (PPI), 4,36 (VA) e 2,63 (AC).

\subsection{Número de dias para o florescimento (NDF)}

A média para NDF foi de 53,2 dias com variância média iqual a 4,9 (dias) ${ }^{2}$; os cruzamentos que apresentaram maior numero de dias para o florescimento foram 
(Viçoja $\times$ SOC 81-228) e (IAC-10 x GO 81-11646), e o com menor NDF foi (Viçoja x FT 81-1706), sendo que entre os parentais os materiais Bossier e FT 81-1706 foram os mais precoces com 49,5 dias para NDF.

CAMPOS (1979), RAW \& MEMON (1979), FREIRE-FILHO (1988), NASS (1989) encontraram heterose e heterobeltiose predominantemente negativa para esse caráter, o que está de acordo com as estimativas encontradas no presente estudo. Esses autores acima citados confirmam a dominância do florescimento precoce, sendo exceção o trabalho de VEATCH $(1930)$

\section{2. Altura da planta no florescimento (APF)}

A média para APF foi de $39,9 \mathrm{~cm}$ com variância de $26,1 \mathrm{~cm}^{2}$; houve grande variaçăo, indo de $51,5 \mathrm{~cm}$ no cruzamento (Bossier $x$ SoC 81-228) a 28,7 no cruzamento (Davis x FT 81-2706). A heterose foi predominantemente positiva, o que confirma a tendência dos híbridos serem maiores que a média dos respectivos parentais.

Vários cruzamentos apresentaram variâncias relativamente altas, os quais refletem a existencia de ampla variabilidade para APF. FREIRE FILHO (1988) relata que os principais fz’s tendem e se colocar entre a média dos parentais e o parental superior, evidenciando a ocorrencia 
de domimancia parcial para maior estatura no florescimento. Já PASCHAL II \& WILCOX (1975) relatam que as progenies tenderam a ser intermediárias entre os respectivos parentais, o mesmo resultado e relatado por CAMpos (1979) E RAW \& MENON (1979).

\section{3. Número de dias para a maturidade (NDM}

A média para NDM foi de 132,2 dias, variando de 118,0 a 148,0 dias. No geral as progenies se distribuiram dentro do ciclo semi-precoce (NDM: 120 a 135 dias); entretanto, há possibilidade de seleção tanto para o ciclo precoce (menos que 120 dias) como para semi-tardio (mais que 135 dias). A variância foi de 57,3 (dias) ${ }^{2}$. A heterose média foi de $-6,4$, indicando que as progênies fz situaram-se em torno da media dos parentais com uma tendência de dominância parcial para maturidade precoce. Esses resultados são concordantes com PAsCHAL II \& WILCOX (1975), CAMPOS (1979), RAW \& MENON (1979), FREIRE FILHO (1988) e NASS (1989). Já PALUDZYSZYN FILHO (1982) chama a atenção para o fato de que, ocasionalmente, sob reduços expressivas do NDM, podem ocorrer decréscimos indiretos na produção de grăos. Neste estudo, a correlação de SPERMAM foi bastante baixa, porém positiva $\left(r_{s}=0,051114\right)$, entre per'iodo reprodutivo (pr) e produção. 


\title{
4. 4. Altura da planta na maturidade CAPM
}

\begin{abstract}
Para esse caráter a média geral foi igual à $52,1 \mathrm{~cm}$, variando de 65,3 a 36,7 com uma variáncia de 50,7 $(c m)^{2}$. Houve alguma variação para esse caráter entre os parentais, sendo que os cultivares podem não estar totalmente homozigoticos para esse carater, ou então podem sofrer maior influência ambiental; o mesmo ocorreu com FREIRE FILHO (1989) e NASS (1989).

A heterose foi predominantemente positiva, o que está de acordo com WEISS et alii (1947), BRIM \& COCKERMAN (1961) e WEBER et alii (1970) que relataram a ocarrência de heterose no sentido do aumento do porte.

Já o trabalho de RAW \& MENON (1979) apresentou heterose media negativa para APM, enquanto PASCHAL II \& WILCOX (1975) e FREIRE FILHO (1988) relataram que as progênies Fi's no primeiro caso e Fz's no segundo tenderam a ser intermediárias entre os parentais.
\end{abstract}

\subsection{Acamamento $(A C)$ e valor agronômico $(V A)$}

Esses dois caracteres tem em comum a avaliacão subjetiva atraves de uma escala de notas visuais e a análise realizada com dados transformados para $\sqrt{x+1}$. E importante lembrar que para AC as menores notas correspondem 
aos menores graus de acamamento, e portanto, a um melhor comportamento.

Para AC a média geral foi 1,7, variando de 2,6 a 1,1, sendo a variância iqual a 0,1 ; esse caráter apresentou o coeficiente de variação igual a $2,63 \%$. E também bom lembrar que como a experimento foi conduzido em covas, isso pode mascarar as estimativas do carater.

As estimativas de heterose, em sua maioria foram negativas e apresentaram uma media de $-7,3$. Esses resultados indicam que as progenies tenderam a apresentar menor grau de acamamento que a média dos respectivos parentais, apresentando com isso maior vigor. FREIRE FILHO (1988) E PASCHAL II \& WILCOX (1975), relatam que rão obtiveram nentum $F_{2}$ no primeiro caso e $F_{1}$ no segundo que superasse o parental mais resistente, ou seja, as progenies tenderam a ser mais resistentes que a media dos respectivos parentais, mas foram menos resistentes que o respectivo parental mais resistente.

Para VA a média foi de 2,8 variando de 1,5 a 4,4. Esse experimento se caracterizou pela boa performance,tanto dos parentais como das progênies fz's, o que resultou em alto valor agronómico. $\quad$ o coeficiente de variação para esse carater foi $4,36 \%$.

o VA variou bastante nesse experimento, bem mais do que o encontrado por FREIRE FILHO (1988) e NASS (1989). Esse resultado sugere que há uma ampla variaçăo 
para esse carater. Apesar dos parentais apresentarem bom valor agronómico, houve casos onde VA da progénie superou os respectivos parentais. Já FREIRE FILHO (1988) relata que o VA da progenie foi inferior ao VA do respectivo parental superior, na analise de um dialelo $10 \times 10$ de soja precoce. BRIM (1973), relatou que esquemas de avaliaçă visual são efetivos somente para caracteres com alta herdabilidade, o que deve ser visto com cautela para VA, pois as notas visuais são dadas muitas vezes levando-se em consideração caracteres de baixa herdabilidade como por exemplo produção de grãos por planta.

\section{6. Produçฐ̃o de grãos por planta (PPI)}

Nesse carater o presente estudo se diferenciou dos demais, sendo a media de ppI iqual a 74,9 gramas por planta (gPp), bastante superior aos resultados obtidOS por FREIRE FILHO (1988), NASS (1988) E HIROMOTO (1990). Como destaque poderia-se citar os cruzamentos $(I A C-10 \times 6081-11646)$ e (IAC-10 10 IAC-12) respectivamente com médias de 110,2 e 100,1 gpp. Entre as parentais, os destaques foram IAC-1 e GO 81-11646. Entre as progenies variou de 110,1 à 50,5 com variancia média iqual a $147,49^{2}$. 0 coeficiente de variaçăo para esse carater fai igual a $16,2 \%$. 
A heterose foi predominantemente positiva, variando de $-18,65$ (Bossier $x$ IAC-12) a 27,3 (Viçoja $x$ IAC-1). Esses resultados estão de acordo com FREIRE FILHO (1988) e NASS (1989), sendo que as progennies distribuiram-se amplamente em torno da média dos parentais com uma pequena tendencia de superioridade.

Convém, mais uma vez, lembrar que uma vez que o experimento foi feito em covas, não são muito seguras comparaçses de produtividade feitas com FREIRE FILHO (1988) e HIROMOTO (1990) que avaliaram as progenies em fileiras; já NASS (1989) utilizou covas e fileiras.

\subsection{Analise da Capacidade de Combinação}

Nesta análise, como os tratamentos do dialelo foram compostos pelos parentais mais os 45 cruzamentos sem os reciprocos, utilizou-se o método 2, e em decorrencia da escolha deliberada dos parentais foi usado o modelo misto B, onde os efeitos de tratamento 5 ão fixos (GRIFFING, $1956 \mathrm{~b}$ ).

$$
\text { A capacidade geral de combinação (CGC) }
$$

decorre principalmente da variancia genética aditiva e da variáncia epistática aditiva $x$ aditiva, enquanto que a capacidade especifica de combinaçăo (CEC) resulta da variancia genética dominante e de varios tipos de componentes da variância epistática (GRIFFING, 1956a e KEMPTHORNE \& CURNOW, 
1961). Estudos feitos em um ano e em um local podem ter os efeitos de CGC e CEC superestimados em consequencia do não isolamento das interaç8es com esses fatores. PASCHAL II \& WILCOX (1975) relatam que embora essas interaçós de CGC e CEC com anos tenham sido significativoa, elas foram de pequena magnitude, particularmente em relação a CGC. Caso isso possa ser generalizado em soja, os dados obtidos podem ser considerados satisfatórios para avaliação da CGC e CEC (desde que não seja um ano atípico e nem um local especial).

4.7.1. Capacidade geral de combinação

Desde que $\Sigma_{g i}=0$, quando a estimativa de gi do parental i tem baixo valor absoluto a CGC do parental i está em torno da CGC média de todos as parentais. Por outro lado, estimativas de $g^{i}$ de alto valor absoluto indicam que o parental i tem CGC superior (gi positivo) ou inferior (gi negativol aos parentais com os quais está sendo comparado.

\subsubsection{Capacidade especifica de combinaçăo}

A exemplo da CGC, para a CEC quando a estimativa do $S_{i j}$ de um determinado hibrido tem baixo valor absoluto, indica que o hibrido se comporta conforme o esperado a partir dos efeitos aditivos e possivelmente epistaticos aditivo $x$ aditivo. Por outro lado, quando a estimativa de $S_{i j}$ de um dado hibrido tem alto valor absoluto (negativo ou positivo) indica que o cruzamento em questão 
superior ou inferior ao esperado com base no CGC dos parentais.

\subsubsection{Análise dialélica}

Neste estudo, para todos os caracteres, as estimativas de $S_{i j}$ apresentaram grande variaçăo, o que indica a existencia de diversidade entre os parentais; este fato está de acordo com FREIRE FILHO (1988) e NASS (1989). Entretanto; para soja é importante ressaltar que o produto final são linhagens homozigóticas, as quais encerram somente efeitos aditivos e espistaticos do tipo aditivo $x$ aditivo. Neste contexto, a CEC, por $5 i$ so, tem um valor limitado para - processo de seleção.

Neste estudo, encontraram-se valores de -8,67833 a 8,43003 para os gi's dos parentais para PPI, sendo quatro estimativas negativas e seis positivas, sendo que os parentais com maior valor absoluto de gi positivos foram IAC-12 e GO 81-11646, enquanto que os maiores valores absolutos negativos foram FT 81-2706 e Davis. O parental GO 81-11646 foi o que apresentou o maior valor absoluto positivo $(g i=8,43003)$. Isto indica que esse parental contribui para um aumento medio de 8 gramas por cruzamento. Para PPI a CEC variou bastante, tendo 26 estimativas negativas e 29 positivas, sendo que a heterose foi predominantemente positiva para esse caráter. 
Para NDF houve cinco estimativas positivas e cinco negativas para CGC, sendo que o parental Bossier teve - maior valor absoluto negativo $(-2,064997)$, ou seja, contribui em media com menos dois dias para a florescimento, enquanto que o parental IAC-12 teve o maior valor absoluto positivo $(1,835014)$, ou seja, contribui com um aumento médio de 2 dias no florescimento. Esse material pode ser fonte de genes para aumento do períado juvenil. Os valores ceC variam também bastante para esse caráter, tendo 33 estimativas negativas e 22 positivas, sendo a heterose predominantemente positiva.

Para APF houve tres estimativas negativas e sete positivas para CGC, sendo que o parental SOC 81-228 teve o maior valor absoluto positivo $(1,7366)$ enquanto que o parental IAC-1 teve o maior valor absoluto negativo $(-3,213329)$. Para CEC houve 29 estimativas negativas e 26 positivas variando de $-10,2757$ para $S_{(3,9)}$ a 9,8909 para $5(1,2)$ - A heterose foi predominantemente positiva com 32 estimativas positivas, variando de 19,05 (Viçoja $x$ soc 81.228) a $-8,95$ (Davis $\times$ IAC-12). Esses resultados estão razoavelmente de acordo com FREIRE FILHO (1988) e NASS $\{1989)$.

Para NDM houve quatro estimativas negativas e seis positivas para CGC, sendo que o parental FT 81-2706 apresentou o maior valor absoluto negativo $(-7,23)$, enquanto que o maior valor absoluto foi 5,62 para o parental Bossier. 
Ja para o carbter APM a variação da CGC foi mais estreita, variando de 3,20 para BR-1-Fosca a -3,27 para Viçoja.

Houve seis estimativas negativas para CGC para o caráter $A C$; esse fato demonstra porque as progénies tenderam a apresentar menor grau de acamamento que a media dos respectivos parentais. Nesse carater, destacou-se o parental SoC 81-228 com o maior valor absoluto negativo igual a $-0,088$, sendo que o cultivar Davis apresentou a maior valor absoluto positivo igual a $0,083$.

Para o caráter VA houve cinco estimativas positivas e cinco negativas para CGC variando de 0,063 para - parental IAC-10 e -0,063 para o parental SOC $81-228$. A alta produça de grăos, aliada à baixa incidencia de acamamento, foram fundamentais para as altas notas dadas a esse carater. Entretanto, tanto a alta produção quanto o acamamento podem ter sido favorecidos pela competiçăo mínima do plantio em covas. Esta dúvida será esclarecida futuramente quando as progenies das geraçós avançadas de endogamia forem testadas na forma de fileiras.

- efeito da capacidade de combinação de um cultivar com ele mesmo (Sii), em muitos casos, têm sido julgado como parâmetro sem significado. Entretanto, CRUz \& VENCOVSKY (1989) demonstram que a estimativa de sii é de fundamental importancia para indicar a direção dos desvios de dominânicia. Este parâmetro será negativo quando os desvios forem predominantemente positivos, e positivos em 
caso contrario. Esses autores demonstram também que o estimador Sii é uma medida de divergencia genética do parental i em relação à medida dos outros parentais incluśdos no dialelo. Esta divergência sera maior quanto maior for a valor absoluto de Sii. Resta saber o valor de Sii comparativamente à gi (CGC) como indicadores de diversidade genética em espécies autógamas como a soja.

Para produção de grãos houve boa variação de $S_{i j}$ indo de 15,112 para $S_{(5,5)}$ à $-16,421 S_{(0,6)}$. A maioria das estimativas para esse carater foram negativas indicando desvios positivos de dominância. Como citado acima, houve grande variação nesta estimativa, indicando tambem boa divergencia entre os parentais. Entretanto, a variaçăo encontrada foi menor do que a encontrada por NASS (1989) para esse mesmo caráter.

Nos demais caracteres estudados encontrou-se também ampla variação, demonstrando a divergencia dos parentais. Sob esse aspecto destacou-se $S_{(3,3)}$ para APF onde essa estimativa foi a mais alta com valor positivo $(9,8909)$ entre todas as estimativas de Sii desse carater.

A relação CGC e CEC foi avaliada segundo BAKER (1978) para o modelo com efeito de tratamentos fixos. A expressão utilizada envolve os quadrados médios de CGC/(CGC+CEC). A relaçăo encontrada foi $91,92 \%$ para NDF, 91,76 para APF, 94,12 para NDM, 89,51 para APM, 91,78 para AC, 94,43 para VA e 94,98 para PPI, o que demonstra a 
importância da açăo aditiva nestes caracteres. Resultados semel hantes foram encontrados por FREIRE FILHO (1988) e NASS (1989). Esse importante efeito da ação gênica aditiva demonstra que o uso de seleção recorrente é fundamental para - aproveitamento da variabilidade genética produzida através de cruzamentos dialélicos.

Essas estimativas podem estar superestimadas, principalmente por causa do erro experimental. Entretanto, CRUZ \& VENCOUSKY (1989) relatam que "a influencia da variância será nula apenas quando as variedades testadas no dialelo tiverem, en média, uma frequência gênica igual a $1 / 2$ em todas os locos". Este fato pode ser esperado ocorrer em um dialelo envolvendo parentais homozigóticos e progênies F's, como é o caso da presente pesquisa.

De um modo geral, baixos valores sij indicaram que os híbridos comportaram-se conforme o esperado a partir da CGC de seus parentais para os caracteres analisados. Entretanto, houve destaque para alguns cruzamentos em todos os caracteres analisados.

Em soja os principais componentes da Variância genetica são a ação genetica aditiva e as açợ gênicas do tipo aditivo $x$ aditivo (ST. MARTIN, 1981 ). Entretanto, houve destaque para sij para alguns cruzamentos para o caráter PPI, demonstrando que efeitos não aditivos nă devem ser desprexados, conforme o sugerido anteriormente por $\operatorname{BRIM}(1973)$ 


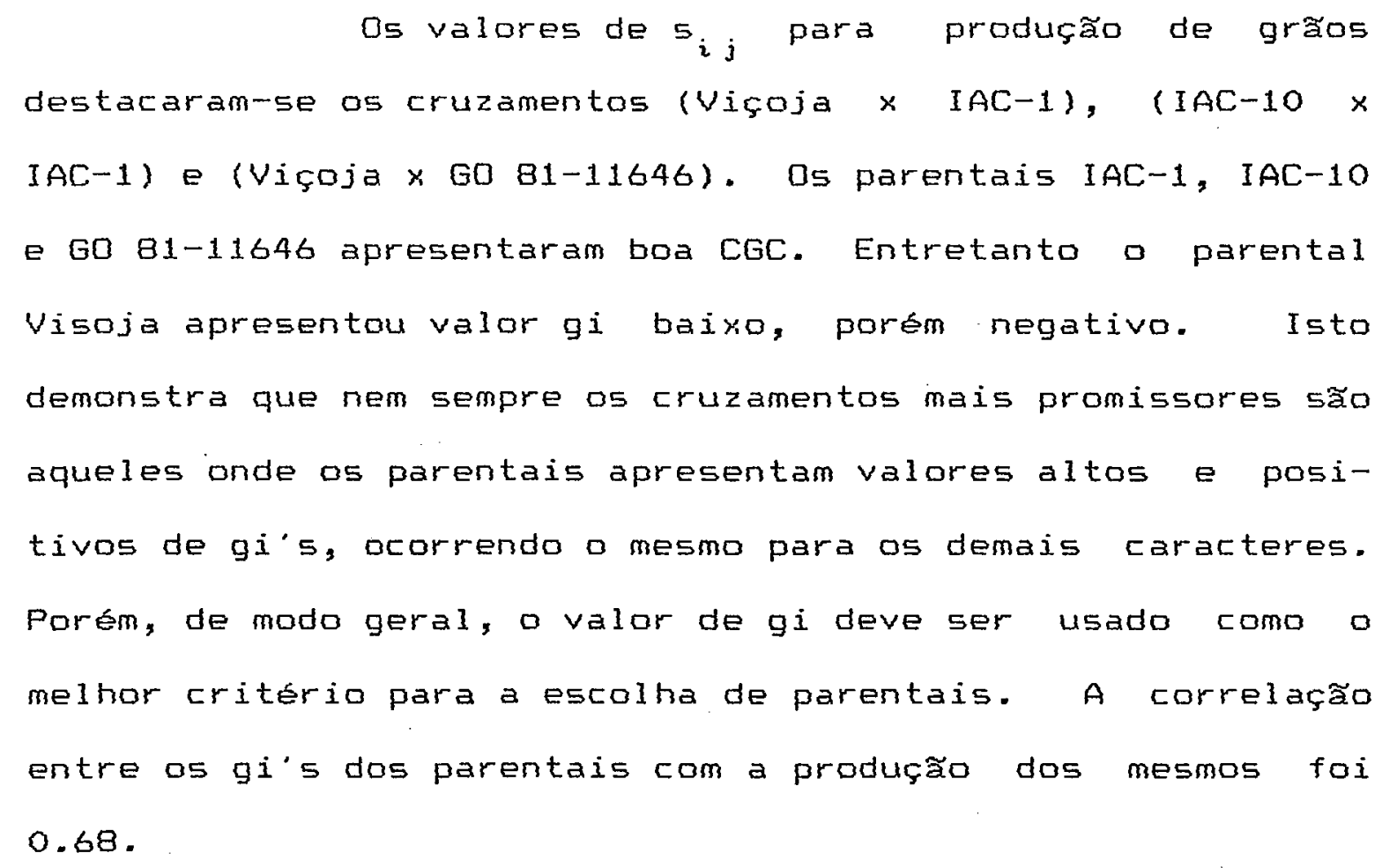




\section{CONCLUSÕES}

$$
\text { as resultados permitiram as seguintes }
$$

conc lusరัอง:

a. O delineamento em latice não foi mais eficiente do que o delineamento em blocos casualizados.

b. Para produção de grãos, apesar da correlação relativamente alta $\left\langle_{s}=0,6848\right)$ entre as ordens de Classificação dos Parentais para média e efeitod da capacidade geral de combinação, algumas discrepâncias importantes ocorreram: $6081-11646(1$ e 1$), \operatorname{IAC}-1$ (2 e 3$)$, SOC $81-228(3$ e 4$), \operatorname{IAC}-10(4$ e 5$)$, Davis $(5$ e 9), IAC-12 (6 e 2), Viçoja (7 e 7), FT 81-2706 (8 e 10), RB-1-Fosca (9 e 6), Bossier (10 e 8).

c. Cerca de 56\% dos cruzamentas superaram as respectivos parentais em produtividade dos grãos. Os cruzamentos mais promissores foram: (IAC-1 x GO 81-11646), $($ IAC-10 $\times$ IAC-12), (GO 81-11646 $\times$ SOC 81-228) e (BOSSier $\times$ $(A C-1)$ 
d. A maioria dos cruzamentos mostraram-5e mais variáveis que os respectivos parentais, o que indica a possibilidade de se conseguir sucesso com a pratica de seleção dentro de cruzamentos.

f. o nivel de diversidade genética dos caracteres indicou que o conjunto de parentais e apropriado para a sintese de população com base genética ampla, visando-se programas de seleção recorrente. 


\section{REFERÊNCIAS BIBLIOGRÁFICAS}

ALLARD, R.W. Principios do melhoramento genetico das plantas. Trad. de A. Blumensthein e outros. Rio de Janeiro, USAID, Edgard Blücher, 1971. 381p.

BAKER, R.J. Issues in diallel analysis. Crop Science, Madison, 18(4): 533-5, 1978 .

BERNARD, R.L. Two major genes for time of flowwring and maturity in soybeans. Crop Science, Madison, 11: 242-4, 1980.

BERTRAND, J.P.; LAURENT, C.; LECLERQ, V. o mundo da soja. São Paulo, Hicitec/Edusp, 1987. 139p.

BRIM, C.A. Quantitative genetics and breeding. In: CALDWELL, B.E., ed. Soybeans: improvement, production and uses. Madison, Am. Soc. of Agron., 1973. p.155-86.

BRIM, C.A. \& BURTON, J.W. Recurrent selection in soybeans II; Selection for increased percent protein in seeds. Crop Science, madison, 19: 494-8, 1979.

BRIM, C.A. \& COCKERHAM, C.C. The inheritance of quantitative character in soybean. Crop Science, Madison, 1: $1987-90,1961$. 
BRIM, C.A. \& YOUNG, M.F.

Inheritance of male sterile character in soybeans. Crop Seience, Madisan, 11 : 5646, 1971 .

BONATO, E.R. Herança do tempo para o florescimento e para a maturidade em variantes naturais de soja (GLyxine max (L.) Merrij1). Piracicaba, 1989. 166p. (Doutorado ESALQ/USP).

BURTON, W.J. Quantitative genetics; resulta relevant to soybean breeding. In:WILCOX, J.R., ed. Soybeans: improvement, production and uses. Library of Congress Cataloging, Madison, 1987. P.135-97.

BURTON, 3.W. \& BRIM, C.A. Recurrent selection in soybeans,

III. Selection for increased percent ail in seeds. Crop Science, Madison, $21: 31-4,1981$.

BUZZEL, R.I. Inheritance of soybean flowering. Canadian Journal of Genetics and Cytology, Ottawa, 13: 703-7, 1971.

BUZZEL, R.I. \& VOLDENE, H.D. Inheritance of ineritivity to lang daylenth. Soybeans Genetics Newletter, Ames, 7: $26-9,1980$.

CAMPOS, L.A.C. Estudo da heterose, da herdabilidade e de correlaçốs de algumas caracteristicas agronomicas em cruzamentos de soja (Glycine max (L.) Merrill). Viçosa, 1979. 76p. (Tese Mestrado - UFV).

COMPTON, W.A. Recurrent selection in self-pollinated crops without extensive crossing. Crop Science, Madison, 8: $773,1968$. 
CRUZ, C.D. \& VENCOUSKY, R. Comparação de alguns métodos de análise dialelica. Revista Brasileira de Genetica, Ribeirão Preto, $12(2): 425-38,1989$.

DELANNAY, X.; RODGERS, D.M.; PALMER, R.G. Relative genetic contributions among ancetral lines to moth american soybean cultivars. Crop Science, Madison, 23: 944-949, 1983.

DUVICK, D.N. Genetic diversity in major farm crops on the farm and in reserve. Economic Botany, Bronx, NY 38(2): $161-78,1984$.

FAO. Quarterly Bulletin of Statistics - 1991, Rome, 4\{2\}: $54,1991$.

FEHR, W.R. Breeding. In: NORMAM, A.G., ed. Soybean physiology, agronomy and utilization. New York, Academic Press, 1978. p.119-55.

FEHR, W.R. \& CAVINESS, C.E. Stages of soybean development. Iowa, USA, Iowa State Univ., 1977. 12p. (Special Report, 80).

FEHR, W.R. Principles of cultivar development. Theary and tectmiques, val. 1. New York, Macmillan Publishing Company, 1987. p.95-6.

FEHR, W.R. \& ORTIZ, L.B. Recurrent selection for yield in soybeans. Journal Agriculture of the University of Puerto Rico, Porto Rico, 59: 222-32, 1975.

FREIRE FILHO, F.R. Analise genética de um dialelo entre genótipos precoces de soja (Glycine max (L.) Merrill). Piracicaba, 1988. 224p. (Doutorado - ESALQ/USP). 
GARDNER, C.O. \& EBERHART, S.A. Analysis and interpretation of the variety cross diallel and related population. Biometrics, Tallahasee, 22: 439-52, 1966.

GOMES, F.P. \& GARCIA, C.H. Látices ou reticulados quadrados. Instituto de Pesquisas e Estudos florestais. Piracicaba, 1991. 26p.

GRIFFING, B. A generalized treatment of the use of diallel crosses in quantitative inheritance. Heredity, Edinburg, 10: 31-50, 1956a.

GRIFFING, B. Concept of general and especific combining ability in relation to diallel crossing systems. Australian Journal of Biological Science, 9: 463-93, $1956 \mathrm{~b}$.

HANSON, W.D.; PROBST, A.M.; CALDWELL, B.E. Avaliation of a population of soybean genotypes with implications for improving self-pollinated crops. Crop Science, Madison, $7: 99-103,1967$.

HAYMAN, B.I. The analysis of variance of diallel tables. Biometrics, Tallahasee, 10: 235-44, 1954a.

HAYMAN, B.I. The theory and analysis of diallel cross. Genetics, Tallahasee, 39: 789-809, 1954b.

HIROMOTO, D.M. Parentais exóticos como fonte de genes para precocidade e produtividade de soja (Glycine max (L.) Merril1). Piracicaba, 1990. 110p. (Mestrado - Escola Superior de Agriculltura "Luiz de Queiraz"/USP).

HIROMOTO, D.M. \& VELLO, N.A. The genetic base of Brazilian soybean (Glycine max (L.) Merrill) cultivars. Revista Brasileira de Genetica, Ribeirão Preto, 9: 295-306; 1986. 
JENSEN, N.F. A diallel selective mating system for cereal breeding. Crop Science, Madison, 10: 629-36, 1970.

JOHNSON, M.W. \& BERNARD, R.L. Soybean genetics and breeding. In: NORMAN, A.G., ed. The soybean. New York, Academic Press, 1963. P.1-73.

KEMPTHORNE, O. \& CURNOW, R.N. The diallel cross. Biotrics, Raleigh, $17: 229-50,1961$.

KENWDORTH, W.J. \& BRIM, C.A. Recurrent selection in soybeans; I. Seed yield. Crop Science, Madison, 19: 315$8,1979$.

KHADR, F.H. \& FREY, R.J. Effectiveness of recurrent selection in oat breeding. Crop Science, Madison, 5: 349-54, 1965.

KIIHL, R.A.S. Inheritance studies of two characteristics in soybean (Glycine max (L.) Merrill). I. Resistance to soybean mosaic virus; II. Late flowering under short-day conditions. Mississipi, 1976. 56p. (Ph.D. - Mississipi State University).

LAZZARINI, S.P.G. \& DITT, A.M. Preços praticados internamente diminuem a competitividade internacional. Informe CEP/DESR, Piracicaba, 4(12): 33, julho 1991 .

LAZZARINI, S.P.G. \& DITT, A.M. Sojá crédito à uRSS pode aquecer o mercado internacional. Informe CEP/DESR, Piracicaba, 4(12): 33, dez. 1991b.

LEFFEL, R.C. \& WEISS, M.G. Analysis of diallel crosses among ten varieties of soybeans. Agronomy Journal, Madison, 50: 528-34, 1958 . 
MCBLAIN, B.A. \& BERNARD, R.L. A new gene affecting the time of flowering and maturity in soybeans. The Journal Heredity, Washington, 78: 160-2, 1987.

NASS, L.L. Potencialidade de genótipos de soja lGlycine max (L.) Merrill)) para cultivo de inverno avaliada por cruzamentos dialélicos. Piracicaba, 112p. (Tese-Mestrado). Escola Superior de Agricultura "Luiz de Queiroz"/USP.

PALUDZYSIYN FILHO, E. Análise do potencial genético de cultivares de soja (Glycine max (L.) Merrill) através de cruzamentos dialelicos. Piracicaba, 1982. 94p. (Tese Mestrado - ESALQ/USP).

PASCHAL II, E.H. \& WILCOX, R. Heterosis and cobrining abrining in exotic soybean germoplasm Crop Science, Madison, 15: 344-7, 1975 .

PATERNIANI, E. \& MIRANDA FILHO, J.B. Melhoramento de popuIaÇסES. In: PATERNIANI, E. \& VIEGAS, G.P., Ed. Melhoramento e Produçăo de Milho. Campinas, Fundação Cargil1, 1987. V.1, cap. 6, p.217-74.

RAW, R.N. \& MENON, P.M. Heterosis in a ten-parental diallel cross in soybean. Indian Journal of Agricultural Sciences, New Delhi, 49: 322-4, 1979.

SEDIYAMA, T.; ALMEIDA, L.A.; MIYASAKA, S., KHIIL, R.A.S. Genética e métodas de melhoramenta. In: MIYASAKA \& MEDINA, ed. A soja no Brasil. Campinas, Ital, 1981. p.209-40.

SPRAQUE, G.F. Plant breeding. Annual Review of Genetics, 1: $269-94,1967$. 
SRIVASTAVA, R.L.; SAYENA, 3.K.; AHMAD, Z.; BHATIA, R.S. Genetics of yield, and yield component traits in soybean. Indian Journal of Genetics and Plant Beeding, New Delsi, 38: $7-10,1978$.

ST. MARTIN, K.S. Epistasis and soybean breeding.

Soybean Genetics Newsletter, Ames, 8: 104-7, 1981.

TALUKDAR, P. \& K.S. BAINS. Genotype $\times$ Enviroment interaction in a Diallel cross of Wheat. Journal of Plant breeding, $89(3)$ : 197-205, 1982.

TENDRIH, L. O avanço da soja na Paisagem brasileira. Ciencia hoje, Rio de Janeiro 6(33): 25-31, 1987.

TOLEDO, J.F.F. \& KIHL, R.A.S. Métodos de análise dialélica do modelo genético en controle das caracterfsticas dias para floraça e número de folhas trifoliadas em soja. Pesquisa Agropecuária Brasileira, Brasilia, 17: 745-55, $1982 \mathrm{a}$.

TOLEDO, J.F.F. R KIHL, R.A.S. Análise do modelo genetico envolvido no controle de dias para o floresciménto em soja. Pesquisa Agropecuária Brasileira, Brasilia, 17: $623-31,1982 \mathrm{~b}$.

VEATH, C. Vigor in soybeans as affected by hybridity. Journal of the American Society of Agronomy, Madison, 22: $288-310,1930$.

VELLo, N.A. Efeitos da Intradução de Germoplasma Exótico sobre a produtividade e relaçóes com a base genética dos cultivares de soja (Glycine max (L.) Merrill). Piracicaba, 1985. 91p. (Tese Livre-Docencia) Escala Superior de Agricultura "Luiz de Queiroz"/USP. 
VELLO, N.A.; HIROMOTO, D.M.; AZEVEDO FILHO, A.J.B.V. Coefficient of parentage of Brazilian soybean germplasm. Revista Brasileira de Genética, Ribeirão Preto, 11 : $679-97,1988$.

VELLo, N.A. Ampliaçăo da base genética do germoplasma e me3horamento da soja na ESALG/USP. In: CAMARA, G.M.S.; MARCOS FD, J.; OLIVEIRA, E.A.M. Simpósio sobre a cultura e produtividade da soja. Piracicaba, FEALQ, 1992a. $p \cdot 60-81.27 p$.

VELLO, N.A. Métodos de melhoramento da soja. In a CAMARA, G.M.S.; MARCOS FO, 3.; OLIVEIRA, E.A.M. Simpśsio sobre a cultura e produtividade da soja. Piracicaba, FEALQ, 1992b. P. 41-59.

VENCOVSKY, R. Análise de cruzamentos dialélicos entre variedades pelo metodo de Gardner \& Eberhart. Relatório Cientifico do Instituto de Genética, Piracicaba, (2): 99111,1969 .

VENCOVSKY, R. Alguns aspectos téricos e aplicados relativos a cruzamentos dialélicos de variedades. Piracicaba, 1970. 59p. (Tese Livre-Docência) Escola Superior de Agricultura "Luiz de Queiroz"/usP.

WEBER, C.R.; EMPIG, L.T.; THORNE, J.C. Heterotic performance and combining ability of tuoway $F$. soybean hybrids. Crop Science, Madison, 10: 159-60, 1970.

WEISS, M.G.; WEBER, C.R.; KALTON, R.R. Early generation testing in soybeans. Journal of American Society of Agronomy, Washington, 39: 791-811, 1947 . 
TABELAS 
Tabela 1. Eficiência e coeficiente de.variação da anāítise em Tátice $8 \times 8$ para.sete caracteres de soja. semi-precoce. Diale10.10x10, Piracicaba, semeadura em $21 / 11 / 89$

\begin{tabular}{lcc}
\hline Caracteres & $\begin{array}{c}\text { Eficiência do } \\
\text { Tátice (\%) }\end{array}$ & CV (\%) \\
\hline Nümero de dias para o florescimento & 103,74 & 6,57 \\
A1tura da planta no florestimento & 100,84 & 12,78 \\
Nūmero de dias para maturidade & 100,56 & 5,75 \\
A1tura da planta na maturidade & 108,64 & 13,63 \\
Acamamento & 105,29 & 3,84 \\
Valor Agronômico & 102,37 & 5,23 \\
Produção de grãos por planta & 101,92 & 16,15 \\
\hline
\end{tabular}



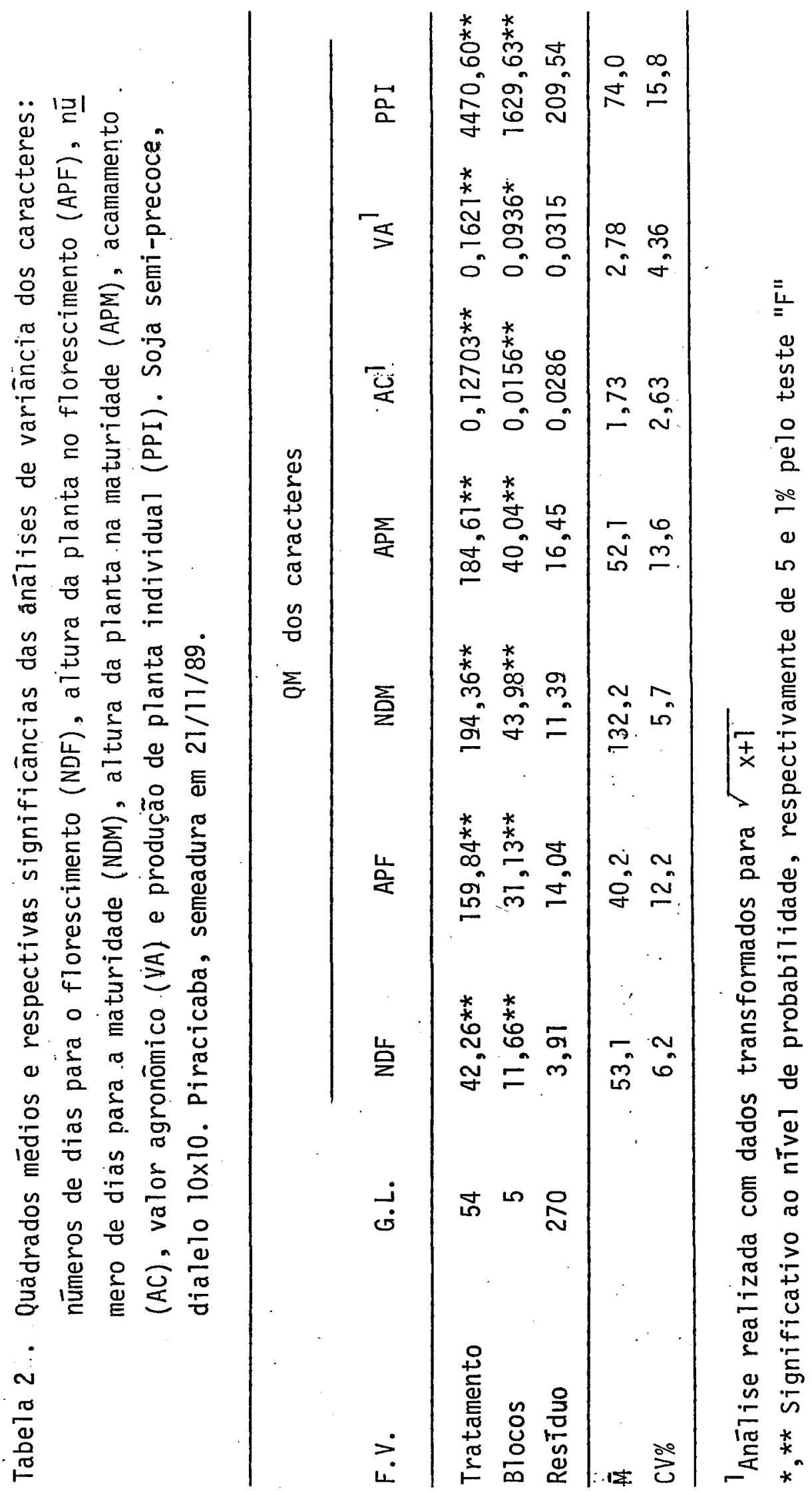
Tabela 3. Mëdias $(\bar{X})$ e variāncia $\left(s^{2}\right)$ para nūmero de dias para o florescimento (NDF) e altura da planta no florescimento (APF). Piracicaba, semeadura em $21 / 11 / 89$.

\begin{tabular}{|c|c|c|c|c|}
\hline \multirow{2}{*}{ Parentais } & \multicolumn{2}{|c|}{ NDF } & \multicolumn{2}{|c|}{ APF } \\
\hline & $\bar{x}$ & $s^{2}$ & $\bar{x}$ & $s^{2}$ \\
\hline 1: Davis & 52,4 & 3,863 & 40,2 & 9,432 \\
\hline 2: Bossier & 49,5 & 1,447 & 49,8 & 11,463 \\
\hline 3: Viçoja & 61,6 & 3,396 & 45,2 & 12,568 \\
\hline 4: IAC-10 & 54,1 & $2,9.64$ & 44,1 & 11,491 \\
\hline 5: IAC-12 & 54,3 & 1,515 & 28,7 & 8,061 \\
\hline 6: IAC-1 & 57,4 & 4,454 & 33,0 & 11,600 \\
\hline 7: BR-1-Fosca & 53,4 & 4,242 & 43,7 & 10,386 \\
\hline 8: G0 81-11646 & 53,7 & 1,841 & 37,2 & 7,311 \\
\hline 9: SOC $81-228$ & 56,1 & 1,808 & 43,7 & 5,897 \\
\hline 10: FT 81-2706 & 49,9 & 2,678 & 41,3 & 12,618 \\
\hline $\bar{M}$ & 54,3 & 2,815 & 40,7 & 10,083 \\
\hline
\end{tabular}


Tabela 4. Médias $(\bar{x})$, variāncia $\left(s^{2}\right)$, heterose $(h \%)$ e herdabilidade $\left(h^{2}\right)$ para número de dias para o floresciménto (NDF) e altura da plan ta no florescimento (APF) de 45 cruzamentos dialéticos em $F_{2}$. Piracicaba, semeadura em 21/11/89.

\begin{tabular}{|c|c|c|c|c|c|c|c|c|}
\hline \multirow{2}{*}{ Trat. al } & \multicolumn{4}{|c|}{ NDF } & \multicolumn{4}{|c|}{ APF } \\
\hline & $\bar{x}$ & $b(\%)$ & $s^{2}$ & $h^{2}$ & 8 & $h(\%)$ & $s^{2}$ & $h^{2}$ \\
\hline $1 \times 2$ & 49,5 & $-6,455$ & 22,855 & 0,897 & 43,8 & $-5,266$ & 46,964 & 0,779 . \\
\hline $1 \times 3$ & 52,8 & $-14,792$ & 11,788 & 0,693 & 39,5 & $-15,021$ & 15,182 & 0,383 \\
\hline $1 \times 4$ & 49,8 & $-13,044$ & 6,878 & 0,619 & 36,1 & $-28,938$ & 57,818 & 0,812 \\
\hline $1 \times 5$ & 51,5 & $-7,236$ & 8,872 & 0,727 & 33,1 & $-8,088$ & 27,800 & 0,612 \\
\hline $1 \times 6$ & 55,4 & 3,808 & 13,091 & 0,683 & 38,3 & 9,608 & 27,955 & 0,682 \\
\hline $1 \times 7$ & 55,8 & $10,79 !$ & 14,164 & 0,714 & 35,8 & $-13,686$ & 22,164 & 0,553 \\
\hline $1 \times 8$ & 50,1 & $-11,316$ & 8,491 & 0,689 & 39,1 & 2,177 & 27,691 & 0,700 \\
\hline $1 \times 9$ & 47,2 & $-24,004$ & $7,9.45$ & 0,667 & 36,7 & $-25,114$ & 29,634 & 0,798 \\
\hline $7 \times 10$ & 49,1 & $-6,809$ & 13,758 & 0,769 & 41,1 & 5,726 & 24,361 & 0,552 \\
\hline $2 \times 3$ & 51,7 & $-13,934$ & 8,750 & 0,747 & 29,8 & $-37,692$ & 38,265 & 0,686 \\
\hline $2 \times 4$ & 48,7 & $-12,164$ & 14,218 & 0,892 & 37,5 & 12,957 & 59,401 & 0,807 \\
\hline $2 \times 5$ & 55,7 & 14,373 & 6,731 & 0,780 & 38,3 & $-47,918$ & 32,380 & 0,703 \\
\hline $2 \times 6$ & 51,2 & $-8,568$ & 12,564 & 0,798 & 43,1 & $-18,778$ & 28,929 & 0,601 \\
\hline $2 \times 7$ & 50,6 & $-3,539$ & 7,824 & 0,683 & 36,8 & $-36,178$ & 33,437 & 0,674 \\
\hline $2 \times 8$ & 51,7 & $-0,121$ & 11,855 & 0,862 & 43,5 & $--1,880$ & 25,291 & 0,638 \\
\hline $2 \times 9$ & 50,2 & $-10,0.12$ & 2,194 & 0,563 & 41,5 & $-42,703$ & 19., 194 & 0,572 \\
\hline $2 \times 70$ & 50,6 & 4,851 & $10,80.0$ & 0,820 & 43,8 & $-8,816$ & 32,073 & 0,625 \\
\hline $3 \times 4$ & 50,5 & $-25,441$ & 19,778 & $0 ; 706$ & 39,5 & $-.14,948$ & $29 ; 854$ & 0,592 \\
\hline $3 \times 5$ & 59,6 & 6,647 & 8,447 & 0,624 & 33,4 & $-19,172$ & 25,356 & 0,603 \\
\hline $3 \times 6$ & 51,1 & $-28,39.9$ & 5,447 & 0,584 & 32,2 & $-35,617$ & 34,646 & 0,652 \\
\hline $3 \times 7$ & 52,4 & $-16,979$ & 6,673 & 0,370 & 33,6 & $-43,929$ & 19,590 & 0,417 \\
\hline $3 \times 8$ & 52,4 & $6,59.5$ & 4,267 & 0,628 & 48,7 & $8,29.1$ & 18,687 & 0,513 \\
\hline $3 \times 9$ & 59,6 & $-34,946$ & 8,023 & 0,628 & 49,6 & $-17,113$ & 20,606 & 0,582 \\
\hline $3 \times 10$ & 48,8 & $-21,666$ & 7,822 & 0,729 & 43,2 & $-0,032$ & $36,46.5$ & 0,655 \\
\hline $4 \times 5$ & 49,6 & 18,031 & 7,478 & 0,570 & 35,1 & $-7,081$ & 23,677 & 0,594 \\
\hline $4 \times 6$ & 59,3 & $-8,095$ & 14,056 & 0,742 & 37,9 & $-3,129$ & 40,544 & 0,715 \\
\hline $4 \times 7$ & 53,5 & $21,9.35$ & 13,167 & 0,731 & 43,1 & $-3,456$ & 18,606 & 0,587 \\
\hline
\end{tabular}


Tabela 4. Continuação.

\begin{tabular}{|c|c|c|c|c|c|c|c|c|}
\hline \multirow{2}{*}{ Trat. } & \multicolumn{4}{|c|}{ NDF } & \multicolumn{4}{|c|}{ APF } \\
\hline & $x^{-}$ & $h(\%)$. & $s^{2}$ & $\bar{h}^{2}$ & 8 . & $h(\%)$ & $s^{2}$ & $h^{2}$ \\
\hline $4 \times 8$ & 59,7 & 1,549 & 6,429 & 0,637 & 44,1 & 16,981 & 27,503 & 0,667 \\
\hline $4 \times 9$ & 54,3 & $-0,003$ & 4,629 & 0,500 & 43,9 & 0,330 & 25,758 & 0,680 \\
\hline $4 \times 10$ & 54,9 & 6,791 & $4,9.33$ & 0,435 & 37,9 & $-22,286$ & 34,933 & 0,655 \\
\hline $5 \times 6$ & 54,2 & $-3,364$ & 12,447 & 0,791 & 30,1 & $-4,729$ & 29,407 & 0,668 \\
\hline $5 \times 7$ & 53,5 & $-1,205$ & 7,902 & 0,679 & 35,7 & $-2,636$ & 16,750 & 0,454 \\
\hline $5 \times 8$ & 50,2 & $-4,005$ & 15,841 & $0,89.5$ & 39,2 & 38,479 & 21,432 & 0,642 \\
\hline $5 \times 9$ & 53,6 & $-5,945$ & 9,377 & 0,824 & 36,9 & 18,732 & 43,823 & 0,825 \\
\hline $5 \times 10$ & 55,2 & 13,301 & 12,956 & 0,858 & 39,5 & 11,404 & 28,767 & 0,649 \\
\hline $6 \times 7$ & 56,7 & 4,579 & 11,166 & 0,611 & 38,7 & 1,948 & 18,591 & 0,409 \\
\hline $6 \times 8$ & 49,7 & $-20,989$ & 5,018 & 0,436 & 37,7 & 14,953 & 29,618 & 0,689 \\
\hline $6 \times 9$ & 49,8 & $-24,403$ & 12,515 & 0,773 & 42,6 & 22,218 & 18,242 & 0,547 \\
\hline $6 \times 70$ & 49,3 & $-13,072$ & 22,515 & 0,848 & 42,6 & 29,667 & 25,909 & 0,337 \\
\hline $7 \times 8$ & 54,5 & 3,601 & 9,174 & 0,695 & 40,5 & 0,200 & 24,473 & 0,664 \\
\hline $7 \times 9$ & 53,6 & $-4,4: 01$ & 14,773 & 0,813 & 37,5 & $-28,032$ & 44,874 & 0,680 \\
\hline $7 \times 10$ & 54,1 & 6,871 & 16,440 & 0,797 & 43,1 & 2,627 & 32,606 & 0,606 \\
\hline $8 \times 9$ & 54,7 & $-0,979$ & 5,248 & 0,652 & 35,1 & $-26,777$ & 29,061 & 0,847 \\
\hline $8 \times 10$ & 56,9 & 20,982 & 12,992 & 0,837 & 44,6 & 27,774 & 24,473 & 0,705 \\
\hline $9 \times 10$ & 49,9 & $-10,614$ & 5,901 & 0,631 & 39,3 & $-14,827$ & 47,333 & 0,818 \\
\hline $\bar{M}$ & & $-4,414$ & 10,328 & 0,667 & & $-7,081$ & 29,629 & 0,668 \\
\hline
\end{tabular}

a/: Os nūmeros de 1 a 10 representam parentais identificados na Tabela 3 . 
Tabela 5 - Produção de planta individual (gpp). Média $(\bar{M})$, heterose $h(\%)$, heterobettiose e herdabilidade $\left(h^{2}\right)$ - Piracicaba, semeadura em $21 / 11 / 91$

\begin{tabular}{|c|c|c|c|c|c|}
\hline Genōtidos ${ }^{a /}$ & $\bar{M}$ & $s^{2}$ & $h(\%)$ & $h^{2}$ & Heterobeltiose \\
\hline 1: Davis & 71 & 336 & & & \\
\hline 2: Bossier & 51 & 373 & & & \\
\hline 3: Viçoja & 65 & 875 & & & \\
\hline 4: $I A C-10$ & 73 & 534 & & & \\
\hline 5: IAC-12 & 67 & 736 & & & \\
\hline 6: IAC-1 & 80 & 1112 & & & \\
\hline 7: BR-1-Fosca & 56 & 572 & & & \\
\hline 8: GO $81-11646$ & 81 & 1003 & & & \\
\hline 9: SOC $87-228$ & 74 & 1117 & & & \\
\hline \multicolumn{6}{|c|}{ 10: FT_81-2706 60} \\
\hline $1 \times 2$ & 69 & 407 & 26,2295 & 0,2032 & $-5,6338$ \\
\hline $1 \times 3$ & 67 & 1151 & $-2,9412$ & 0,5289 & $-11,2676$ \\
\hline $1 \times 4$ & 81 & 1105 & 25,0000 & 0,6167 & 21,9178 \\
\hline$\times 5$ & 66 & 1182 & $-8,6957$ & 0,5793 & $-14,0845$ \\
\hline $1 \times 6$ & 85 & 902 & $\therefore \quad 25,1656$ & 0,3223 & 12,5000 \\
\hline $7 \times 7$ & 56 & 596 & $-23,6220$ & 0,2644 & $-42,2535$ \\
\hline $1 \times 8$ & 85 & 1241 & 23,6842 & 0,5322 & $-2,7027$ \\
\hline $1 \times 9$ & 73 & 1500 & 1,3793 & 0,5916 & $-29,7297$ \\
\hline $1 \times 10$ & 62 & 1032 & $-10,6879$ & 0,4411 & $-9,2308$ \\
\hline $2 \times 3$ & 67 & 908 & 31,0345 & 0,4236 & 6,1538 \\
\hline $2 \times 4$ & 75 & 1336 & 41,9354 & 0,5497 & 5,4795 \\
\hline $2 \times 5$ & 67 & 1030 & 27,1186 & 0,5340 & 0,0000 \\
\hline $2 \times 6$ & 94 & 1804 & 87,0229 & 0,6730 & 35,0000 \\
\hline $2 \times 7$ & 77 & 891 & 87,8505 & 0,5251 & 75,0000 \\
\hline $2 \times 8$ & 88 & 1878 & 66,6670 & 0,7016 & 17,2840 \\
\hline $2 \times 9$ & 63 & 834 & $-9,09.09$ & 0,2910 & $-29,7297$ \\
\hline $2 \times 10$ & 68 & 907 & 45,0450 & 0,3863 & 26,6667 \\
\hline $3 \times 4$ & 88 & 2060 & 55,0725 & 0,6682 & 41,0959 \\
\hline
\end{tabular}


Tabela 5. Continuação.

\begin{tabular}{|c|c|c|c|c|c|}
\hline Genōtinos a/ & $\bar{M}$ & $s^{2}$ & $h(\%)$ & $h^{2}$ & Heterobeltiose \\
\hline $3 \times 5$ & 67 & 833 & 3,0303 & 0,0366 & 0,0000 \\
\hline $3 \times 6$ & 93 & 3032 & 56,5517 & 0,6747 & 32,5000 \\
\hline $3 \times 7$ & 67 & 747 & 1,6529 & 0,0529 & $-12,3077$ \\
\hline $3 \times 8$ & 81 & 872 & 21,9178 & 0,0000 & 0,0000 \\
\hline $3 \times 9$ & 72 & 797 & $7,19.42$ & 0,0000 & $-5,4054$ \\
\hline $3 \times 10$ & 67 & 1330 & 14,400 & 0,5286 & 23,3333 \\
\hline $4 \times 5$ & 100 & 1749 & 85,7143 & 0,4206 & 73,9726 \\
\hline $4 \times 6$ & 84 & 1179 & 19,6070 & 0,5312 & 10,0000 \\
\hline $4 \times 7$ & 80 & 954 & 48,0620 & 0,2329 & 19,1781 \\
\hline $4 \times 8$ & 89 & 2135 & 31,1688 & 0,6383 & 19,7521 \\
\hline $4 \times 9$ & 85 & 741 & 31,2925 & 0,0188 & 29,7297 \\
\hline $4 \times 10$ & 77 & 1132 & 31,5789 & 0,2008 & 10,9589 \\
\hline $.5 \times 6$ & 65 & 881 & $-23,1293$ & 0,2635 & $-37,5000$ \\
\hline$-5 \times 7$ & 76 & 1305 & 47,1545 & 0,3416 & 26,8657 \\
\hline $5 \times 8$ & 75 & 1233 & 2,7027 & 0,2646 & $-14,8148$ \\
\hline$: 5 \times 9$ & 73 & 724 & 7,0922 & 0,0000 & $-2,7027$ \\
\hline $5 \times 10$. & 72 & 1995 & 26,7717 & 0,6002 & 14,9254 \\
\hline $6 \times 7$ & 73 & 1646 & 14,7059 & 0,3584 & $-17,5000$ \\
\hline $6 \times 8$ & 110 & 2350 & $72,29.19$ & 0,5257 & 71,6049 \\
\hline $6 \times 9$ & 9.1 & 1200 & 36,3636 & 0,1256 & 27,5000 \\
\hline $6 \times 10$ & 74 & 1074 & 11,4286 & 0,2947 & $-15,0000$ \\
\hline $7 \times 8$ & 90 & 1282 & 62,7737 & 0,3765 & 25,0000 \\
\hline $.7 \times 9$ & 76 & 9.54 & 33,8462 & 0,2112 & $-12,3457$ \\
\hline $7 \times 10$ & 58. & 493 & 0,0000 & 0,0000 & $-6,6667$ \\
\hline $8 \times 9$ & 98 & 1443 & 52,9032 & 0,3094 & 41,9753 \\
\hline $8 \times 10$ & 72 & 1162 & 4,2533 & 0,1424 & $-22,2222$ \\
\hline $9 \times 10$ & 55 & 638 & $-35,8209$ & 0,0000 & $-51,3514$ \\
\hline
\end{tabular}

a/: Os nūmeros 1 a 10 representam parentais identificados na Tabela 3. 
Tabela 6 . Médias para PPI $(\mathrm{g})$, NDF (dias), APF $(\mathrm{cm})$, NDM (dias), APM (cm), VA e AC. Piracicaba, semeadura em 21/11/89.

\begin{tabular}{|c|c|c|c|c|c|c|c|}
\hline Genōtipos $^{a /}$ & PPI & $\mathrm{NDF}$ & APF & NDM & APM & VA & $A C$ \\
\hline 1: Davis & 70,5 & 52,4 & 40,2 & 118,0 & 43,2 & 2,54 & 1,94 \\
\hline 2: Bossier. & 50,5 & 49,5 & 49,8 & 125,2 & 55,4 & 2,63 & 1,63 \\
\hline 3: Viçoja & 64,9 & 61,6 & 45,2 & 142,0 & 50,5 & 2,58 & 1,14 \\
\hline 4: IAC-10 & 73,4 & 54,1 & 44,1 & 123,3 & 57,2 & 3,04 & 1,56 \\
\hline 5: IAC-12 & 67,8 & 54,3 & 28,7 & 125,5 & 43,0 & 2,86 & 1,94 \\
\hline 6: IAC-1 & 80,5 & 57,4 & 33,0 & 136,0 & 61,3 & 3,25 & 2,18 \\
\hline 7: BR-1-Fosca & 55,6 & 53,4 & 43,7 & 138,8 & 54,9 & 2,36 & 1,77 \\
\hline 8: G0 81-11646 & 81,4 & 57,3 & 37,2 & 124,6 & 60,8 & 3,14 & 1,93 \\
\hline 9: SOC $81-228$ & 74,2 & 56,1 & 43,7 & 122,4 & 44,2 & 2,67 & 1,14 \\
\hline 10: FT $81-2706$ & 60,2 & 49,9 & 41,3 & 120,3 & 44,0 & 2,89 & 1,36 \\
\hline $1 \times 2$ & 69,4 & 49,5 & 43,8 & 134,3 & 57,5 & 3,61 & 1,62 \\
\hline $1 \times 3$ & 66,8 & 52,8 & 39,5 & 140,0 & 40,3 & 2,08 & 2,13 \\
\hline $1 \times 4$ & 80,8 & 49,8 & 36,1 & 137,5 & 44,6 & 4,01 & 2,63 \\
\hline $1 \times 5$ & 66,1 & 51,5 & 33,7 & 123,0 & 43,4 & 2,53 & 1,94 \\
\hline $1 \times 6$ & 85,3 & 55,4 & 38,3 & 127,8 & 48,4 & 3,26 & 1,78 \\
\hline $1 \times 7$ & 55,8 & 55,8 & 35,8 & 121,4 & 49,0 & 1,94 & 1,57 \\
\hline $1 \times 8$ & 85,1 & 50,1 & $39 ., 1$ & 130,6 & 51,4 & 2,97 & 2,39 \\
\hline $1 \times 9$ & 73,7 & 47,2 & 36,7 & 120,3 & 50,3 & 2,76 & 2,14 \\
\hline $1 \times 10$ & 67,6 & 49,1 & 41,1 & 140,0 & 55,2 & 2,82 & 1,86 \\
\hline $2 \times 3$ & 67,3 & 51,7 & 29,8 & 129,2 & 46,4 & 1,73 & 1,63 \\
\hline $2 \times 4$ & 74,5 & 48,7 & 37,5 & 126,5 & 57,5 & 2,38 & 1,19 \\
\hline $2 \times 5$ & 67,5 & 55,7 & 38,3 & 145,2 & 38,0 & 2,79 & 1,54 \\
\hline $2 \times 6$ & 93,6 & 51,2 & 43,1 & 131,6 & 57,6 & 4,36 & 2,24 \\
\hline $2 \times 7$ & 77,2 & 50,6 & 36,8 & 143,4 & 46,5 & 2,60 & 1,95 \\
\hline $2 \times 8$ & 89,7 & 51,7 & 43,5 & 136,5 & 58,2 & 3,62 & 1,73 \\
\hline $2 \times 9$ & 62,7 & 50,2 & 51,5 & 142,0 & 60,1 & 2,88 & 1,12 \\
\hline $2 \times 10$ & 67,2 & 50,6 & 43,8 & 127,7 & 45,8 & 2,96 & 1,38 \\
\hline
\end{tabular}


Tabela 6. Continuação.

\begin{tabular}{|c|c|c|c|c|c|c|c|}
\hline Genötipos ${ }^{a /}$ & PPI & NDF & APF & NDM & APM & VA & $A C$ \\
\hline $3 \times 4$ & 87,8 & 50,5 & 39,5 & 122,5 & 57,5 & 3,28 & 1,92 \\
\hline $3 \times 5$ & 67,1 & 59,6 & 33,4 & 124,8 & 50,3 & 2,74 & 1,33 \\
\hline $3 \times 6$ & 93,5 & 51,1 & 32,2 & 134,5 & 46,5 & 3,92 & 1,98 \\
\hline $3 \times 7$ & 60,5 & 52,4 & 33,6 & 142,6 & 60,0 & 2,31 & 1,26 \\
\hline $3 \times 8$ & 81,0 & 52,4 & 48,7 & 138,3 & 57,3 & 3,36 & 2,04 \\
\hline $3 \times 9$ & 72,3 & 59,6 & 49,6 & 140,0 & 41,7 & 2,86 & 1,84 \\
\hline $3 \times 10$ & 67,4 & 48,8 & 43,2 & 129,3 & 48,4 & 2,74 & 1,14 \\
\hline $4 \times 5$ & 100,1 & 49,6 & 35,1 & 138,4 & 47,3 & 3,86 & 1,63 \\
\hline $4 \times 6$ & 84,4 & 59,3 & 37,9 & 136,8 & 56,7 & 3,24 & 1,24 \\
\hline $4 \times 7$ & 80,3 & 53,5 & 43,1 & 135,5 & 62,5 & 2,54 & 1,93 \\
\hline $4 \times 8$ & 88,6 & 59,7 & 44,1 & 132,4 & 63,4 & 4,09 & 2,31 \\
\hline $4 \times 9$ & 85,4 & 59,3 & 43,9 & 140,3 & 64,2 & 3,26 & 2,14 \\
\hline $4 \times 10$ & 77,0 & 54,9 & 47,9 & 128,3 & 46,7 & 2,84 & 1,32 \\
\hline $5 \times 6$ & 65,3 & 54,9 & 30,1 & 123,4 & 48,6 & 2,39 & 1,15 \\
\hline $5 \times 7$ & 75,9 & 53,5 & 37,5 & 142,7 & 53,4 & 2,51 & 1,94 \\
\hline $5 \times 8$ & 75,2 & 50,2 & 39,2 & 148,0 & 55,6 & 2,79 & 1,68 \\
\hline $5 \times 9$ & 73,4 & 53,6 & 36,9 & 126,3 & 53,0 & 1,83 & 1,37 \\
\hline $5 \times 10$ & 72,4 & 55,2 & 39,5 & 134,4 & 63,3 & 2,15 & 1,98 \\
\hline $6 \times 7$ & 73,5 & 56,7 & 38,7 & 134,5 & 61,5 & 3,18 & 1,62 \\
\hline $6 \times 8$ & 110,2 & 49,7 & 37,7 & 129,8 & 54,1 & 4,15 & 2,13 \\
\hline $6 \times 9$ & 91,5 & 49,8 & 42,6 & 125,4 & 57,3 & 3,26 & 1,46 \\
\hline $6 \times 10$ & 74,8 & 49,3 & 42,6 & 131,5 & 65,3 & 2,18 & 2,36 \\
\hline $7 \times 8$ & 90,0 & 54,5 & 40,5 & 128,4 & 60,3 & 3,29 & 1,74 \\
\hline $7 \times 9$ & 76,1 & 53,6 & 37,5 & 130,2 & 58,2 & 2,63 & 1,21 \\
\hline $.7 \times 10$ & 57,7 & 59,1 & 43,1 & 124,8 & 52,3 & 1,88 & 1,46 \\
\hline $8 \times 9$ & 87,6 & 54,7 & 35,1 & 125,7 & 52,5 & 2,36 & 1,85 \\
\hline $8 \times 10$ & 71,2 & 56,2 & 44,6 & 137,7 & 55,3 & 2,46 & 2,32 \\
\hline $9 \times 10$ & 54,5 & 49,9 & 39,3 & 125,4 & 36,7 & $1,53$. & 1,92 \\
\hline $\begin{array}{l}\bar{M} \\
s^{2} \\
\text { cV\% }\end{array}$ & $\begin{array}{r}74,0 \\
136,9 \\
15,8\end{array}$ & $\begin{array}{r}53,1 \\
11,0 \\
6,2\end{array}$ & $\begin{array}{l}40,2 \\
24,4 \\
12,2\end{array}$ & $\begin{array}{r}132,2 \\
57,3 \\
5,7\end{array}$ & $\begin{array}{l}52,1 \\
50,7 \\
13,6\end{array}$ & $\begin{array}{l}2,78 \\
0,42 \\
4,36\end{array}$ & $\begin{array}{l}1,73 \\
0,74 \\
2,63\end{array}$ \\
\hline
\end{tabular}

a/: 0s nūmeros 1 a 10 representam parentais identificados na Tabela 3. 


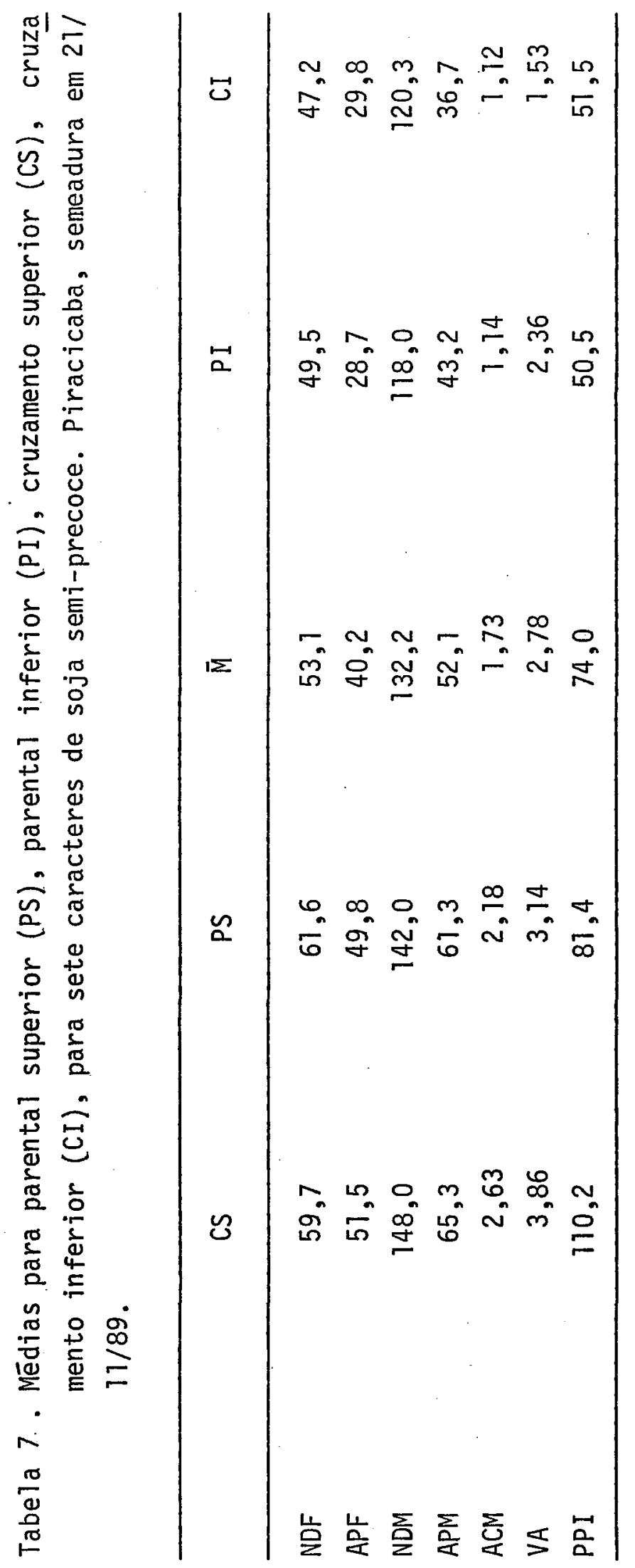


Tabela 8. Anālise de variāncia pelo método 2, modelo misto B de Griffing" (1956 b), a partir de médias de 6 repetições.

\begin{tabular}{|c|c|c|c|c|c|c|}
\hline F.V. & G.L. & SQ & QM & & $E(Q M)$ & $\mathrm{F}$ \\
\hline CGC & $n-1$ & SQg & QMg & $\sigma^{2}+$ & $\frac{(n+2)}{(n-1)} \Sigma g_{i}^{2}$ & $\frac{Q M_{g}}{Q M_{e}}$ \\
\hline CEC & $\frac{n(n-1)}{2}$ & $\mathrm{SQS}_{\mathrm{s}}$ & QMs & $\sigma^{2}+$ & $\frac{2}{n(n-1)} \sum s \leq j j^{2}$ & $\frac{Q M_{s}}{Q M_{e}}$ \\
\hline Resĩduo & $\frac{(r-1) n(n+1)}{2}-1$ & SQe & $\mathrm{QMe}^{\prime}$ & $\sigma^{2}$ & & \\
\hline
\end{tabular}

tendo-se que:

$$
\begin{aligned}
& S Q_{g}=\left.\frac{1}{n+2}\right|_{-} \sum_{i}\left(Y_{i, .}+Y_{i j}\right)^{2}-\frac{4}{n} Y^{2} . . \mid \\
& S Q_{S}=\sum_{i \leq j} Y_{i j}^{2}-\frac{1}{n+2} ;\left(Y_{i}+Y_{i j}\right)^{2} \frac{2}{(n+1)(n+2)} \ldots ; \\
& Q M_{e^{\prime}}=\frac{Q M 4}{b} ;
\end{aligned}
$$

sendo:

$$
\begin{aligned}
Y_{i .}= & \sum_{j} Y_{i, j}=Y_{i 1}+Y_{i 2}+\ldots+Y_{i n} ; \\
Y_{\ldots}= & \sum_{i<j} \cdot Y_{i j}=Y_{11}+Y_{12}+\ldots+Y_{22}+Y_{23}+\ldots+ \\
& +Y_{n 1}+Y_{n 2}+\ldots+Y_{n n}
\end{aligned}
$$




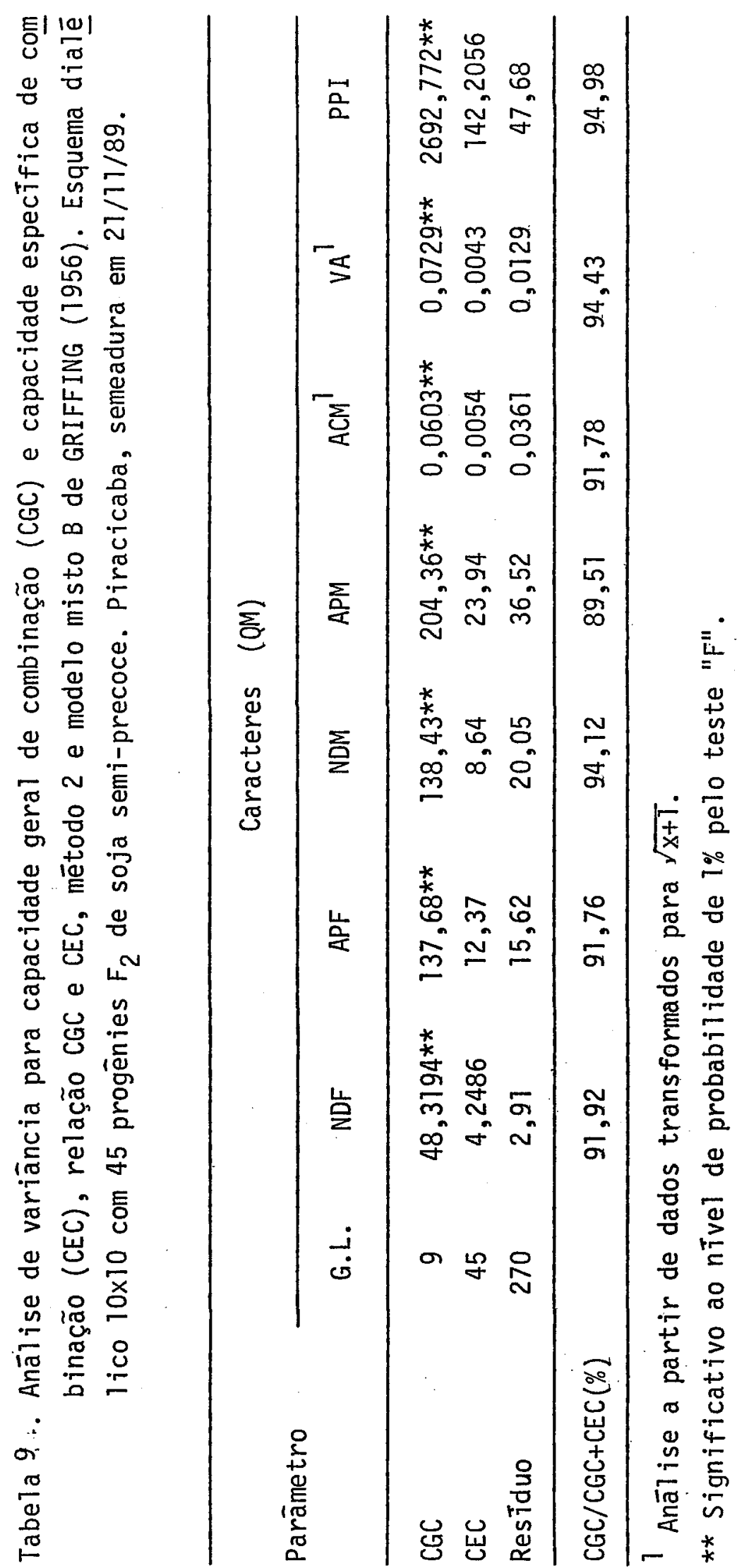




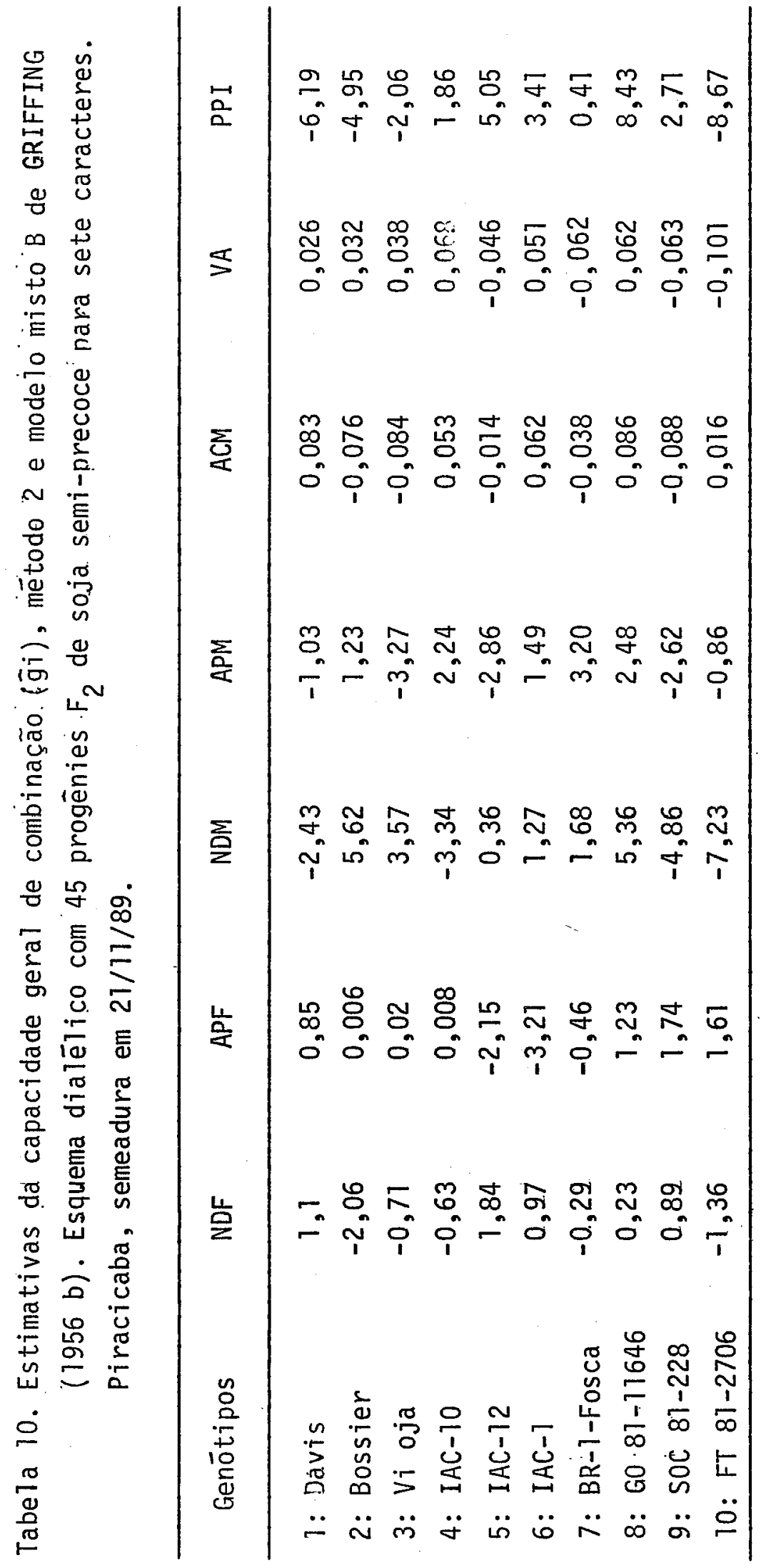


Tabela 11. Estimativas da capacidade específica de combinacão $\left(\hat{s}_{i j}\right)$, método 2 e modelo misto $B$ e Griffing (1956b). Esquema dialélico com 45 progênies $F_{2}$ de soja semi-precoce para sete caracteres. Piracicaba, semeadura em $21 / 11.89$.

\begin{tabular}{|c|c|c|c|c|c|c|c|}
\hline \multirow[b]{2}{*}{ EFEITO } & \multicolumn{7}{|c|}{ ESTIMATI VA } \\
\hline & PPI & NDF & $A P F$ & NDM & APM & $A C$ & VA \\
\hline$S(1,1)$ & 7,995 & $-3,017$ & $-1,250$ & $-4,668$ & $-5,892$ & 0,091 & $-0,178$ \\
\hline$S C 1, \quad 23$ & $-13,254$ & $-2,733$ & 9,174 & $-0,326$ & 6,990 & $-0,057$ & 0,052 \\
\hline SC1. & $-1,737$ & 8,008 & 4,432 & 11,065 & 2,274 & $-0,183$ & $-0,023$ \\
\hline SC1. & 2,837 & 0,424 & 3,449 & $-2,843$ & 6,374 & $-0,010$ & $-0,766$ \\
\hline$S(1,5)$ & $-5,946$ & $-1,833$ & $-9,717$ & $-3,376$ & $-6,517$ & 0,071 & $-0,138$ \\
\hline SC1, & 8,387 & 2,125 & $-4,350$ & 7,431 & 9,265 & 0,279 & $-0,040$ \\
\hline$S C 1,7)$ & $-13,513$ & $-0,800$ & 3,599 & 8,905 & 0,115 & 0,001 & $-0,014$ \\
\hline SC1, & 4,270 & 2,767 & $-4,592$ & $-2,863$ & 5,524 & 0,019 & 0,456 \\
\hline $\mathrm{sC1}, 9)$ & 2,787 & 0,908 & 1,399 & $-3,759$ & $-7,525$ & $-0,240$ & 0,075 \\
\hline $\sec 1,103$ & 0,178 & $-3,033$ & $-0,875$ & $-4,926$ & $-4,425$ & $-0,102$ & 0,270 \\
\hline$S C 2,2 D$ & 4,395 & 0,449 & 4,007 & 5,915 & 9,119 & $-0,231$ & $-0,097$ \\
\hline sce, & $-1,088$ & 2,391 & $-0,434$ & 6,216 & $-7,534$ & 0,109 & $-0,828$ \\
\hline $\operatorname{sc2}, 42$ & 8,987 & $-0,891$ & $-3,717$ & 2,498 & $-5,834$ & 0,542 & $-0,194$ \\
\hline sce, 5$)$ & $-8,890$ & $-1,450$ & $-4,484$ & $-8,734$ & $-5 ; 525$ & 0,001 & $-0,090$ \\
\hline$s C 2, \infty)$ & 11,937 & 3,308 & 1,782 & $-3,626$ & $-3,242$ & $-0,010$ & $-0,336$ \\
\hline sce, 73 & $-14,562$ & 4,983 & $-3,467$ & $-11,293$ & $-5,392$ & $-0,152$ & 0,028 \\
\hline$S(Z, 8)$ & 0,720 & $-1,250$ & $-1,859$ & 0,248 & $-3,484$ & 0,135 & 0,091 \\
\hline sce, & 1.037 & $-4,808$ & $-4,767$ & $-8,718$ & $-1,034$ & 0,077 & 0,410 \\
\hline SC2, 100 & 0,328 & $-0,650$ & $-0,242$ & 11,915 & 7,165 & $-0,002$ & -0.230 \\
\hline sc 3 & $-3,471$ & $-0,087-$ & $-10,275$ & $-10,001$ & $-0,999$ & 0,017 & 0,003 \\
\hline SC 3 & $-0,196$ & $-3,150$ & $-2,459$ & $-7,909$ & 7,540 & $-0,160$ & 0,212 \\
\hline $5 \times 3$ & $-10,379$ & 1,391 & 0,574 & 8,057 & $-10,650$ & $-0,004$ & 0,016 \\
\hline $5<3$, & 17,353 & $-2,250$ & $B, 440$ & $-5,234$ & $B, 432$ & 0,424 & $-0,001$ \\
\hline sc 3 & 3,953 & $-1,575$ & $-2,809$ & 5,298 & $-7,417$ & 0,085 & $-0,001$ \\
\hline$S<3$ & 8,437 & $-1,008$ & 2,399 & 0,740 & 3,790 & $-0,001$ & $-0,423$ \\
\hline
\end{tabular}


Continuacão Tabela 11 .

\begin{tabular}{|c|c|c|c|c|c|c|c|}
\hline \multirow{2}{*}{ EFEI TO } & \multicolumn{6}{|c|}{ ESTIMATI VAS } & \multirow[b]{2}{*}{ VA } \\
\hline & PPI & NDF & $A P F$ & NDM & $A P M$ & $A C$ & \\
\hline $\operatorname{st} 3$ & $-12,846$ & $-3,167$ & 9,890 & 7,573 & 9,240 & $-0,193$ & 0,624 \\
\hline S(3, 10$)$ & 3,445 & $-0,508$ & 2,315 & $-5,793$ & $-1,759$ & $-0,521$ & $-0,352$ \\
\hline $\operatorname{se} 4$ & 9,178 & $-1,433$ & $-0,342$ & $-7,118$ & 4,940 & 0,055 & 0,000 \\
\hline $\operatorname{se} 4, \quad 5)$ & $-14,704$ & 5,208 & $-4,209$ & 7,551 & $-0,950$ & $-0,134$ & 0,476 \\
\hline SC 4 & 13,328 & $-2,433$ & $-4,342$ & 2,456 & $-7,287$ & 0,092 & 0,114 \\
\hline $\operatorname{SC} 4, \quad 73$ & $-16,671$ & 0,142 & $-5,692$ & 9,290 & 3,482 & $-0,241$ & 0,336 \\
\hline $\operatorname{SC} 4$ & $-4,187$ & $-0,392$ & 7,716 & 7,331 & 0,290 & 0,051 & $-0,001$ \\
\hline$S C 4$ & $-7,171$ & 0,149 & 8,107 & 10,365 & $-11,759$ & 0,034 & $-0,001$ \\
\hline$S(4,10)$ & $-0,579$ & $-2,391$ & 1,832 & 0,598 & $-1,758$ & $-0,032$ & $-0,036$ \\
\hline SC5. & 15,112 & $-7,250$ & $-0,275$ & 3,315 & $-2,942$ & $-0,008$ & $-0,292$ \\
\hline SCS & 1,045 & 3,308 & 3,590 & 2,023 & 4,240 & $-0,194$ & $-0,700$ \\
\hline SCS & $-0,054$ & $-1,216$ & 0,040 & $-0,543$ & 7,290 & 0,027 & $-0,116$ \\
\hline sc5. & 0,228 & 4,449 & 5,349 & $-1,301$ & 7,099 & 0,234 & 0,000 \\
\hline SC5, & 2,745 & 3,391 & 4,640 & 7,931 & 12,049 & 0,224 & $-0,068$ \\
\hline$S C 5,10)$ & 5,737 & 1,249 & $-1,234$ & $-3,134$ & $-2,150$ & $-0,015$ & -0.774 \\
\hline$S C B$ & $-16,421$ & $-0,234$ & $-3,142$ & $-11,068$ & $-6,375$ & $-0,260^{\circ}$ & 0,073 \\
\hline SCE, & $-2,821$ & $-0,358$ & 1,507 & 6,905 & $-4,325$ & 0,030 & $-0,436$ \\
\hline SCE. & $-11,537$ & -4.192 & 1,516 & 14,807 & -2.617 & $-0,154$ & 0,757 \\
\hline SCE, & $-7,621$ & $-1,450$ & $-1,292$ & $-5,759$ & -1.667 & -0.072 & $-0,504$ \\
\hline SCE, 100 & 2,770 & 2,408 & 1.432 & 3,273 & 11,932 & 0,078 & 0.372 \\
\hline SC7, 73 & $-2,221$ & 4,117 & $-0,024$ & $-2,501$ & 1,024 & $-0,193$ & 0,314 \\
\hline SC7, & 26,462 & $-3,416$ & $-2,734$ & $-4,859$ & $-8,867$ & 0,057 & 0,004 \\
\hline $5 \times 7, \quad 90$ & 33,478 & $-3,975$ & 1,557 & $-7,925$ & $-0,117$ & $-0,067$ & 0,002 \\
\hline Sc7, 10$)$ & 8,170 & $-2,216$ & 1,782 & $-0,893$ & $11,1 \mathrm{BE}$ & 0,348 & $-0,102$ \\
\hline SC8, & $-1,754$ & 0,849 & $-1,625$ & $-3,918$ & $-1,159$ & -0.041 & 0,109 \\
\hline sc $8, \quad 90$ & -9.937 & $-0,708$ & $-5,134$ & $-0,784$ & 0,290 & $-0,032$ & $-0,032$ \\
\hline$s(8,10)$ & $-16,946$ & 2,049 & 0,590 & -5.251 & $-2,309$ & $-0,137$ & 0,002 \\
\hline sCg, $\quad 9)$ & 7,278 & $-0,267$ & $-8,042$ & $-3,951$ & $-1,859$ & 0,048 & $-0,004$ \\
\hline $5(9,10)$ & 2,970 & 4,191 & 1,582 & 8,981 & 4,240 & 0,409 & $-0,044$ \\
\hline$S(10,10)$ & $-3,037$ & $-0,550$ & $-3,593$ & $-2,384$ & $-11,059$ & 0,040 & $-0,026$ \\
\hline
\end{tabular}


ee.

Tabela 12. Estimativas da capacidade especifica de combinacão $\mathrm{C}_{\mathbf{s}_{i j}}{ }^{3}$, $\mathrm{pa}^{-}$ ra $i=j$, métado 2 e mordelo misto $B$ de Griffing (1956b). Esquema dialélico com 45 progênies $F_{2}$ de soja semi-precoce para sete caracteres. Piracicaba, semeadura em $21 / 11 / 80$.

\begin{tabular}{|c|c|c|c|c|c|c|c|c|c|}
\hline & \multicolumn{6}{|c|}{ ESTIMATI VAS } & \multirow[b]{2}{*}{ VA } \\
\hline \multicolumn{3}{|c|}{ EFEITO } & PPI & NDF & $A P F$ & NDM & $A P M$ & $A C$ & \\
\hline $\operatorname{SC1}$ & , & 13 & 7,995 & $-3,017$ & $-1,259$ & $-4,668$ & $-5,892$ & 0,091 & $-0,178$ \\
\hline scz & , & 2 & 4,395 & 0,449 & 4,007 & 5,915 & 9,1190 & $-0,231$ & $-0,097$ \\
\hline$S \subset 3$ & , & 30 & $-3,471$ & $-0,067$ & $-10,275$ & $-10,001$ & $-0,909$ & 0,017 & 0,003 \\
\hline $\operatorname{sc} 4$ & , & $4)$ & 9,178 & $-1,433$ & $-0,342$ & $-7,118$ & 4,940 & 0,055 & 0,000 \\
\hline SCS & , & $5)$ & 15,112 & $-7,250$ & $-0,275$ & 3,315 & $-2,942$ & $-0,000$ & $-0,292$ \\
\hline$S C E$ & , & 6 & $-16,421$ & $-0,234$ & $-3,142$ & -11.068 & $-6,375$ & $-0,260$ & 0.073 \\
\hline SC 7 & , & 75 & $-2,221$ & 4.117 & $-0,024$ & $-2,501$ & 1,024 & $-0,193$ & 0,314 \\
\hline SC 8 & , & 83 & $-1,754$ & 0,849 & $-1,625$ & $-3,918$ & $-1,159$ & $-0,041$ & 0,169 \\
\hline $\operatorname{scg}$ & , & 9 & 7,278 & $-0,267$ & $-8,042$ & $-3,951$ & $-1,859$ & 0,048 & $-0,004$ \\
\hline $\sec 10$ & & 105 & $-3,037$ & $-0,550$ & $-3,593$ & $-2,384$ & $-11,059$ & 0,040 & $-0,026$ \\
\hline
\end{tabular}




\section{APẼNDICES}


Apêndice 1. Esquema de recombinação em dialelo e cruzamentos mūitîplos entre 40 parentais para sintese de populações com base genētica ampla e aita producão . de grãos. Soja, Piracicaba, SP. (VEL LO, 1992b).

1ạ recombinação: 180 cruzamentos simples (Giparentais)

precoce $(\mathrm{p}):$ dialelo $10 \times 10 \rightarrow 45 \mathrm{~F}_{1}^{\prime} \mathrm{s}(\mathrm{p})$
semi-precoce $(\mathrm{sp}):$ dialelo $10 \times 10 \rightarrow 45 \mathrm{~F}_{1}^{\prime} \mathrm{s}(\mathrm{sp})$
semi-tardio (st $::$ dialelo $10 \times 10 \rightarrow 45 \mathrm{~F}_{1}^{\prime} \mathrm{s}(\mathrm{st})$
tardio $(\mathrm{t}) \quad$ : dialelo $10 \times 10 \rightarrow 45 \mathrm{~F}_{1}^{\prime} \mathrm{s}(\mathrm{t})$

2a. recombinação: 90 cruzamentos quādruplos

$45 F_{1}^{\prime} s(p) 45 F_{1}^{\prime} s(s p) \rightarrow 45\left(F_{1} \times F_{1}\right)(p \times s p)$

$45 F_{1}^{\prime} s(s t) \times 45 F_{1}^{\prime} s(t) \rightarrow 45\left(F_{1} \times F_{1}\right)(s t \times t)$

e endogamia para obter progênies $F_{2}, F_{3}, \ldots, F_{6}$ de cada cruzamento.

3a. recombinação: 45 cruzamentos óctuplos

$45\left(F_{1} \times F_{1}\right)(p \times s p) \times 45\left(F_{1} \times F_{1}\right)(s t \times t)$
$45\left(F_{1} \times F_{1}\right)\left(F_{1} \times F_{1}\right)(p \times s p \times$ st $\times$ st $\times t)$

e endogamia para obter progênies $F_{2}, F_{3}, \ldots, F_{6}$ de cada cruzamento. 
Apēndice 2 . Origem genealōgica dos dez parentais do dialelo 10x10 de soja semi-precoce.

\begin{tabular}{|c|c|}
\hline Parentais & Origem \\
\hline Davis & $D 49-2573 \times N 45-1497$ \\
\hline Bossier & $S-100 \times C N S$ \\
\hline Viçoja & D-49-2491 x Pelican \\
\hline IAC- 10 & Hardee $\times \mathrm{Hill}$ \\
\hline IAC- 12 & Paranā x IAC 73-231 \\
\hline IAC-1 & Aliança Preta x Palmeto \\
\hline BR-1-Fosca & $\mathrm{Hi} 11 \times \mathrm{L}-356$ \\
\hline GO $81-11646$ & Parânā x Mandarin \\
\hline SOC $81-228$ & Desconhecido \\
\hline FT $81-2706$ & Dare $\times$ BR -5 \\
\hline
\end{tabular}


Apēndice 3. Correlação entre capacidade geral de combinação e produção de grãos de dez parentais do diale1o $10 \times 10$ de soja semi precoce.

\begin{tabular}{lrl}
\hline Parentais & GCG & PPI \\
\hline Davis & $-6,19$ & 70,5 \\
Bossier & $-4,95$ & 50,5 \\
Viçoja & $-2,06$ & 64,9 \\
IAC-10 & 1,86 & 73,4 \\
IAC-12 & 5,05 & 67,8 \\
IAC-1 & 3,41 & 80,5 \\
BR-1-FosCa & 0,41 & 55,6 \\
Go 81-11646 & 8,43 & 81,4 \\
SOC 81-228 & 2,71 & 74,2 \\
FT 81-2706 & $-8,67$ & 60,2 \\
\hline
\end{tabular}

$r_{S}(C G C \times P P I)=0,6848$ 